\title{
Changes in Walkable Streets during the COVID-19 Pandemic in a Suburban City in the Osaka Metropolitan Area
}

\author{
Haruka Kato *(D) and Daisuke Matsushita (D) \\ Department of Housing and Environmental Design, Graduate School of Human Life Science, \\ Osaka City University, Osaka 5588585, Japan; matsushita@osaka-cu.ac.jp \\ * Correspondence: haruka-kato@osaka-cu.ac.jp; Tel.: +81-6-6605-2823
}

Citation: Kato, H.; Matsushita, D. Changes in Walkable Streets during the COVID-19 Pandemic in a Suburban City in the Osaka Metropolitan Area. Sustainability 2021, 13, 7442. https://doi.org/ $10.3390 /$ su13137442

Academic Editors: Simona Tondelli and Elisa Conticelli

Received: 9 May 2021

Accepted: 29 June 2021

Published: 2 July 2021

Publisher's Note: MDPI stays neutral with regard to jurisdictional claims in published maps and institutional affiliations.

Copyright: (c) 2021 by the authors. Licensee MDPI, Basel, Switzerland. This article is an open access article distributed under the terms and conditions of the Creative Commons Attribution (CC BY) license (https:// creativecommons.org/licenses/by/ $4.0 /)$.

\begin{abstract}
The purpose of this study was to identify the walkable streets where traffic behavior changed according to each residential cluster during the COVID-19 pandemic. By elucidating the changes, it is possible to identify streets that should be redesigned following the changes in traffic behavior in relation to human mobility. This study analyzed Ibaraki City, a suburban city located in the Osaka Metropolitan Area. The analysis compared the panel data of the GPS Location History for April 2020 and April 2019. The analysis method used was Empirical Bayesian kriging. The results show that the speed significantly increased in the dense, sprawl, mountain, and old NT clusters. It was also found that the number of cyclists increased during the COVID-19 pandemic. The results suggest a need to design walkable streets according to each residential cluster for the post-COVID-19 pandemic era. For example, some car lanes need to be converted to bike lanes in the main neighborhood to create walkable streets in the clusters.
\end{abstract}

Keywords: walkability; COVID-19 pandemic; traffic behavior; human mobility; GPS location history data; Empirical Bayesian kriging; Osaka metropolitan area; SARS-CoV-2

\section{Introduction \\ 1.1. Background: Walkable Neighborhoods during the COVID-19 Pandemic}

A significant social problem in Japan is population decline, with a rapidly increasing number of older adults. For an aging society, walkability in Japanese cities needs to improve [1]. Walkability is defined as a property of a residential environment that promotes walking or cycling with safety, comfort, and the attractions of daily life [1]. Therefore, it is a "new normal" lifestyle to live within walking distance, changing from driving cars to walking or cycling. Improving walkability is expected to contribute not only to the health of residents [2,3] but also to the ecological footprint as a part of urban sustainability [4]. Improving the cities' walkability is an essential issue in many countries worldwide, such as China, where the number of older adults has increased rapidly.

Since January 2020, the Coronavirus Disease 2019 (COVID-19) pandemic has been drastically changing our lifestyles. It has been found that the most crucial feature of severe acute respiratory syndrome coronavirus-2 (SARS-CoV-2) is its transmission via droplets [5]. Therefore, it was suggested that changing human mobility was the most effective way to prevent the spread of SARS-CoV-2 infection [6]. Therefore, cities worldwide requested or demanded that people refrain from leaving their homes, except for essential items. Many Japanese people have begun to live the "new normal," such as refraining from commuting to work [7]. Due to these changes, it was reported that many people did not use public transportation [8]. On the other hand, the World Health Organization (WHO) [9] has advised people to walk or cycle due to a lower risk of SARS-CoV-2 infection. In the United Kingdom, it was confirmed that an increasing number of people have begun to cycle [10]. According to the change in traffic behavior in relation to human mobility, it is necessary to redesign the neighborhood environment because the COVID-19 pandemic is expected to 
continue in the medium-to-long term. Designing walkable neighborhoods is one way that urban planning can contribute toward the "new normal" necessitated by the pandemic.

\subsection{Purpose: Walkable Streets Where Traffic Behavior Has Changed}

The purpose of this study was to examine walkable streets where traffic behavior has changed according to each residential cluster during the COVID-19 pandemic. By elucidating the changes, it is possible to identify streets that should be redesigned following changes in traffic behavior. For this purpose, this study analyzed the panel data of the GPS Location History (LH data) for April 2020 and April 2019. The reason for analyzing April 2020 was that the Japanese government [11] declared a state of emergency for a month from 7 April 2020. The Japanese state of emergency is called the "soft lockdown" [12]. This is because the Japanese government restricted the activities of companies and other organizations, but not of individuals. Therefore, most of the citizens could go out at least minimally, even under the state of emergency declaration. Therefore, it is useful and meaningful to compare 2019 and April 2020 in order to analyze lifestyle behaviors during the COVID-19 pandemic in Japan. These LH data are GPS data obtained from mobile phones. Google [13] released mobility reports for some prefectures, such as the Osaka prefecture, regarding its GPS data. In the prefectures, the Mizuno Laboratory [14] identified unexpectedly populated areas in suburban cities using mobile GPS surveys. Therefore, this study analyzed Ibaraki City in Osaka Prefecture. Ibaraki City is a suburban city located in the Osaka Metropolitan Area. People can travel from Ibaraki City to Osaka City in about $30 \mathrm{~min}$ because of the city's extensive train network. The population of Ibaraki City is approximately 280,000 . Its area is $10 \mathrm{~km}$ east-west and $17 \mathrm{~km}$ north-south. Like other cities, it experienced an increase in the number of SARS-CoV-2 infections during the lockdown period.

\subsection{Novelty: Traffic Behavior Change during the COVID-19 Pandemic}

There are some types of technology to monitor and assess the COVID-19 countermeasures, such as Bluetooth-based contact tracing, GPS-based tracking, symptom checks and self-diagnosis, and trustworthy information for the public [15]. As they help to predict the spread of SARS-CoV-2 infections, human mobility studies using GPS data have attracted much attention. Studies on smartphone GPS data were popularized by González et al. [16], who pointed out that this location data can be used to understand people's movement patterns. In Japan, Seike et al. [17] pointed out the possibility of GPS big data for urban planning. For example, Yamaguchi et al. [18] analyzed living behavior changes during normal, disaster, and recovery periods, using the Kumamoto earthquake disaster as an example. For the COVID-19 pandemic, in China, the spatial distribution of SARS-CoV-2-infected people has been verified using human mobility data from Wuhan [19]. In the United States, it was confirmed that the mobility pattern correlates with a decrease in the number of infected people [20]. In Tokyo, it was reported that human mobility decreased by more than 50\% in April 2020 [21]. The novelty of this study is in elucidating the changes in traffic behavior in relation to human mobility at the street scale in neighborhood environments. The results allow us to investigate specific designs for streets.

Regarding the changes in traffic behavior at the street scale, this study focused on the concept of walkability. In New York, it was found that the higher the walkability of districts, the lower the number of SARS-CoV-2 infections and deaths [22]. In Houston and parts of Seattle, it was found that the number of people who walked and rode bicycles increased with the government's stay home order [23]. Toward the design of walkable neighborhoods, the mayor of Paris, Anne Hidalgo, proposed the realization of a 15-min city by 2024, where people could live without using cars [24], and there has been progress in research toward the realization of this [25]. Ways to increase walkability have been suggested, such as diversifying land use, improving street connectivity, and decreasing traffic accidents and crimes [26]. As streets are spaces where people move by walking and cycling, the design of streets needs to be considered in order to increase walkability 
and to help prevent SARS-CoV-2 infections [27]. Some measures have been implemented in London, such as converting car lanes into bike lanes. The novelty of this study is in identifying the streets where specific traffic behavior has changed to a focus on walking and cycling during the COVID-19 pandemic. The results of this study allow us to consider the design of a new neighborhood environments after the COVID-19 pandemic era.

This manuscript consists of five chapters based on an IMRAD format as follows: materials and methods in Section 2; results in Section 3; discussion in Section 4; and conclusions in Section 5.

\section{Materials and Methods}

\subsection{GPS Location History Data}

This study used LH data. The LH data comprised GPS location history data obtained at regular intervals, approximately every $15 \mathrm{~min}$, depending on the mobile phone type (Figure 1). The data were collected by obtaining consent from mobile phone users who installed particular applications regarding the type of data to be collected, the purpose of use, provision to third parties, and privacy policy. Additionally, users could stop sending the GPS location data by changing their mobile phone's basic settings. The data were obtained through contracts between Agoop Corporation and the Graduate School of Life Science at Osaka City University, where the authors work. This study was approved by the Agoop Corporation, which provides anonymized data. Governments and municipalities have used GPS data provided by Agoop Corporation for the control of COVID-19 infection [28]. In addition, Kato [29] developed an effective method to identify high-density space-time, using GPS LH data provided by the Agoop Corporation. Therefore, the GPS LH data used in this study was validated as high-quality GPS data used in policymaking and research to control the pandemic. The LH data represent approximately $4.2 \%$ of Ibaraki City's population. In Japan, the Agoop Corporation collects daily mobile phone location data and provides anonymized data for research purposes [30]. Using the LH data, this study complies with the "Guidelines for the Use of Device Location Data," common regulation for location data in Japan [31].

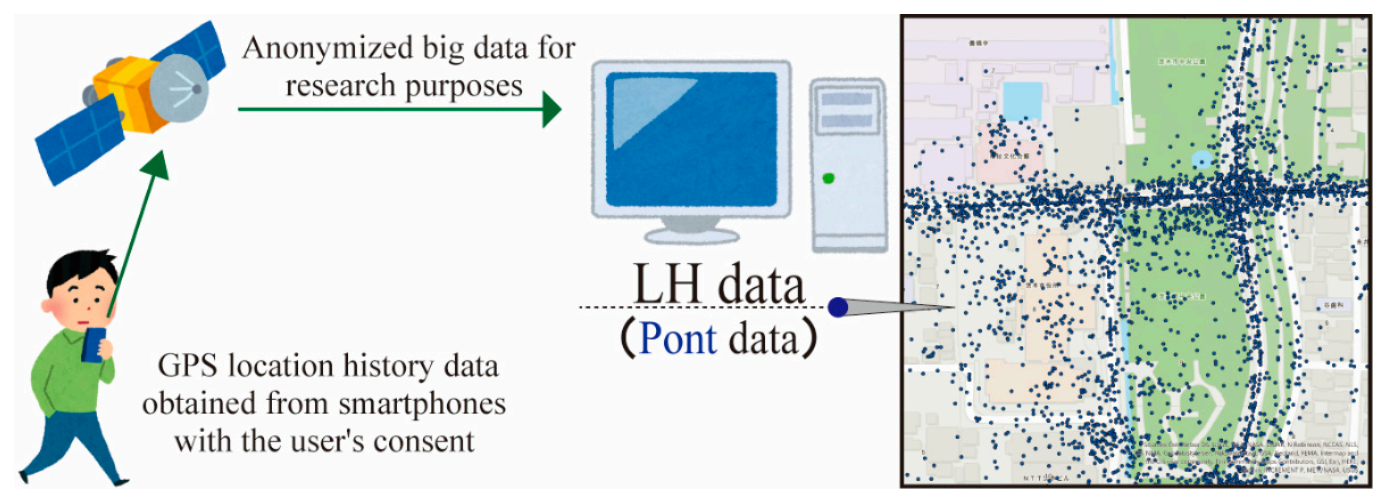

Figure 1. Schematic outlining the collection of LH data.

The LH data mainly comprised the following variables: daily ID, user ID, year, month, day, day of week, hour, minutes, latitude, longitude, OS (Android/iOS), country, GPS accuracy, speed, mesh ID, estimated transportation means, and gender. User IDs are anonymized 96-digit alphanumeric codes that include information which protects personal privacy, such as names, ages, and addresses. The user ID is also a permanent ID that is assigned to each device and enables panel data analysis. This study used year/month/day, latitude/longitude, speed, and transportation means from among these variables, and extracted data on people living in Ibaraki City. Therefore, data relating to people who only passed through Ibaraki City, for example, people traveling from Osaka to Tokyo by train or car, were excluded. 
Using the LH data, this study performed panel data analysis during the state of emergency. This study compared panel data for one month from the intervention date of April 2020, when the government declared a state of emergency, with data from April 2019, one year before. Many cities worldwide were also in lockdown in April 2020. On 7 April 2020, Osaka Prefecture requested that people stay at home and cancel events [32]. Compliance with these requests led to the gradual narrowing of residents' home ranges. Therefore, it was valid to analyze the periods of April 2019 and April 2020 in this study.

\subsection{Empirical Bayesian Kriging}

In this study, the Empirical Bayesian kriging (EBK) method was used. Since LH data contain low-accuracy location data, EBK can evaluate changes in streets effectively, rather than being another interpolation method, such as a natural neighbor and IDW. The EBK is a kind of interpolation method which predicts the values of unmeasured areas according to the values of surrounding points based on the premise that multiple data distributed in space have a spatial correlation. There are two types of interpolation method: deterministic and geostatistical. The kriging method is a geostatistical method. Analysis using the variogram function, which is a probabilistic interrelationship, is more effective at evaluating LH data since the LH data include speed and latitude/longitude data with low accuracy. Kriging was initially developed as a method for mining science [33]. Nowadays, kriging is used to predict the distribution area of PM2.5 [34] and the spreading area of SARS-CoV-2 infections [35]. Compared to the ordinary kriging method, EBK has the advantage of being able to estimate the distribution following the observed facts without the need to assume normality in the observed data as a kind of machine learning for prediction [36-38]. Therefore, EBK can get robust results using the variability of the data, like the sensitivity analysis.

Using EBK, six phases were organized, as shown in Figure 2. Figure 2 contains the data flow chart, which is used in each phase. For phase 1, the LH data observed in April 2020 and April 2019 were plotted separately. For phase 2, the EBK was performed using LH speed data in April 2020 and April 2019. The speed distribution map (EBK-Speed map) that was interpolated by EBK was calculated for April 2020 and April 2019. In the EBK-Speed map, red means faster speed areas, and blue means slower speed areas. For phase 3, the EBK-Speed-Change map was calculated using the differences in raster data between the EBK-Speed map in April 2020 and the EBK-Speed map in April 2019. For phase 4, the scores of each street endpoint in the EBK-Speed map and the EBK-Speed-Change map in April 2020 and April 2019 were calculated. For phase 5, by calculating the average value of the two street endpoints, the scores of each street's EBK-Speed data and EBK-Speed-Change data were calculated. In other words, the street score was calculated from the average value of the edges of endpoint scores on the street. The width of each street was classified into five categories: $\mathrm{W}<3 \mathrm{~m}, 3 \mathrm{~m} \leq \mathrm{W}<5.5 \mathrm{~m}, 5.5 \mathrm{~m} \leq \mathrm{W}<13 \mathrm{~m}, 13 \mathrm{~m} \leq \mathrm{W}<19.5 \mathrm{~m}$, and $19.5 \mathrm{~m} \leq \mathrm{W}$ [39]. The designation of each road was as follows: $\mathrm{W}<3 \mathrm{~m}$ signified narrow streets, $3 \mathrm{~m} \leq \mathrm{W}<5.5 \mathrm{~m}$ signified neighborhood streets, $5.5 \mathrm{~m} \leq \mathrm{W}<13 \mathrm{~m}$ signified main neighborhood streets, $13 \mathrm{~m} \leq \mathrm{W}<19.5 \mathrm{~m}$ signified arterial streets, and $19.5 \mathrm{~m} \leq \mathrm{W}$ signified main arterial streets. For phase 6, the average value of the EBK-Speed data and EBK-SpeedChange data of the neighborhood association, which included the center point of the street, was calculated. In other words, the neighborhood association score was calculated from the average value of the center points of street scores in the neighborhood association. Finally, the validity of the changes was verified from the estimated transportation means of the LH data.

\subsection{Urban Ecological Analysis}

This study clarified the types of residential clusters in the Osaka Metropolitan area using urban ecological analysis. This analysis was based on the neighborhood association (NA) scale, which is same as the zip code. 


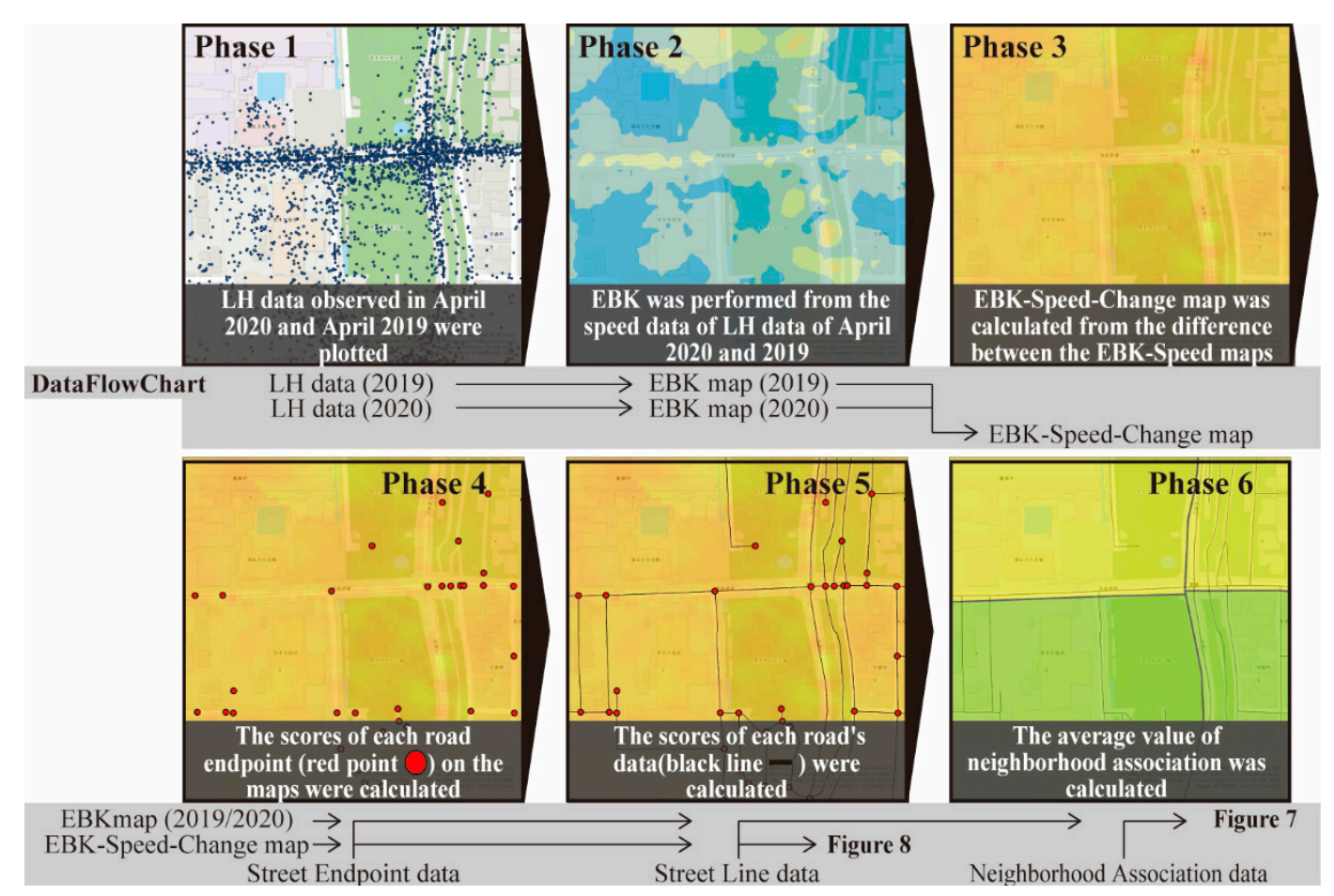

Figure 2. Analysis phases with data flow chart in this study.

According to the Local Autonomy Act in Japan, the NA scale is the smallest scale of community governance determined by the local government. NA has played essential roles as the foundation for consensus on community welfare based on local relationships. Urban ecological analysis analyzes spatial patterns using an inductive method with a wide range of statistical data [40]. Kato et al. [1] evaluated the effectiveness of urban ecological analysis by categorizing residential clusters in the northern part of the Osaka metropolitan area. Kato [4] analyzed the types of clusters using urban ecological analysis in the Osaka metropolitan area, the same region studied in this paper. The validity of the analysis was also assessed [41]. This research consisted of five steps, as detailed in Appendix A.

The residential clusters are shown in Figure 3. The locations of those residential clusters are classifieAd into three categories by the criteria of the urbanized area ratio (\%) and the average distance from the center $(\mathrm{km})$, which is written in Table A1. Central areas are the inner-city $(84.5 \%, 19.3 \mathrm{~km})$ and business center clusters $(86.2 \%, 34.5 \mathrm{~km})$. Suburban areas are the dense $(77.1 \%, 31.2 \mathrm{~km})$, public housing $(72.4 \%, 26.7 \mathrm{~km})$, non-residential $(55.2 \%, 43.9 \mathrm{~km})$, sprawl $(66.2 \%, 38.2 \mathrm{~km})$, high-rise residential $(61.8 \%, 25.9 \mathrm{~km})$, old NewTown (NT) $(59.1 \%, 26.7 \mathrm{~km})$, and suburban agriculture clusters $(21.3 \%, 63.1 \mathrm{~km})$. Rural areas are the mining industry $(45.1 \%, 59.9 \mathrm{~km})$, agriculture $(23.6 \%, 71.6 \mathrm{~km})$, mountain $(40.7 \%, 56.1 \mathrm{~km})$, and rural clusters $(24.9 \%, 52.1 \mathrm{~km})$. The infrastructure typology of each residential cluster was also analyzed based on the average land use area $\left(\mathrm{m}^{2}\right)$, which is written in Table A2. Rice field and farmland areas are large in mining industry $\left(18,644 \mathrm{~m}^{2}\right)$, agriculture $\left(423,887 \mathrm{~m}^{2}\right)$, mountain $\left(24,012 \mathrm{~m}^{2}\right)$, suburban agriculture $\left(180,632 \mathrm{~m}^{2}\right)$, and rural clusters $\left(81,475 \mathrm{~m}^{2}\right)$. The housing areas are large in inner-city $\left(47,374 \mathrm{~m}^{2}\right)$, dense $\left(46,892 \mathrm{~m}^{2}\right)$, public housing $\left(61,492 \mathrm{~m}^{2}\right)$, sprawl $\left(34,236 \mathrm{~m}^{2}\right)$, high-rise residential $\left(72,499 \mathrm{~m}^{2}\right)$ and old NT clusters $\left(48,441 \mathrm{~m}^{2}\right)$.

This study analyzed the clusters of Ibaraki City in the Osaka Metropolitan Area, examining the average EBK-Speed of each cluster in April 2019 and April 2020. This study also analyzed the average EBK-Speed change of each cluster. In Ibaraki City, an important transportation center in the northern part of the Osaka metropolitan area, the EBK-Speed is influenced by the locations of highways and train railroads. Figure 3 shows that there are two railroads and two highways entering from the south of Ibaraki City. 


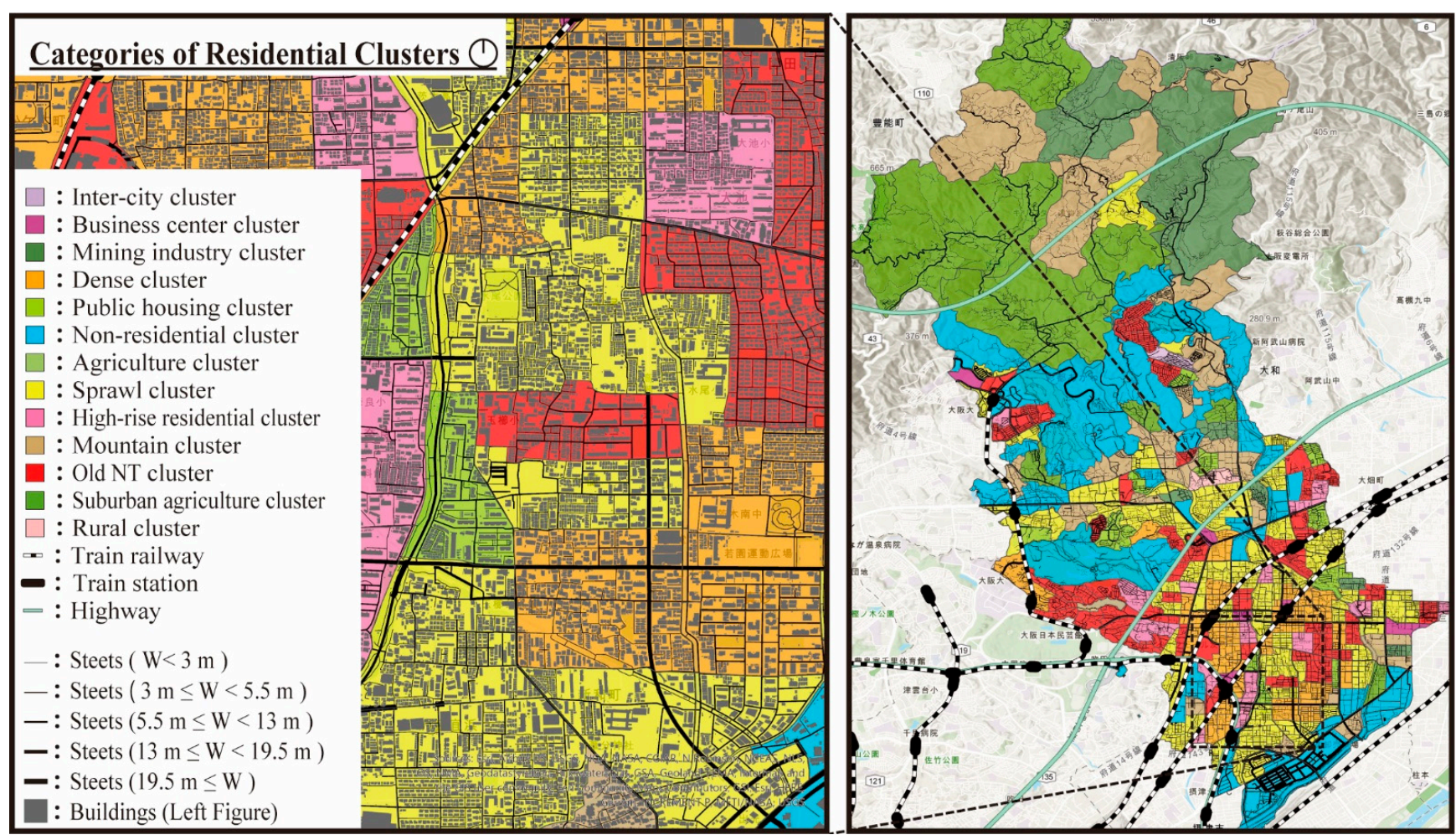

Figure 3. Locations of the residential clusters in Ibaraki City (Figure 3 shows the same results found by Kato [4,41]).

\section{Results}

\subsection{EBK-Speed Map}

EBK-Speed maps were created for April 2020 and April 2019, as shown in Figures 4 and 5, respectively. The analysis was done as part of phase 2, as depicted in Figure 2. In Figures 4 and 5, the classification of the gradations was determined according to the following criteria in terms of the moving speed: $1.0 \mathrm{~m} / \mathrm{s}(=3.6 \mathrm{~km} / \mathrm{h})$ for the speed at which an older adult or a child walks, $3.0 \mathrm{~m} / \mathrm{s}(=10.8 \mathrm{~km} / \mathrm{h})$ for the speed at which a cyclist travels slowly, $5 \mathrm{~m} / \mathrm{s}(=18.0 \mathrm{~km} / \mathrm{h})$ for the speed at which a cyclist usually travels, $8.33 \mathrm{~m} / \mathrm{s}(=30.0 \mathrm{~km} / \mathrm{h})$ for the speed at which cars drive slowly, and $16.67 \mathrm{~m} / \mathrm{s}(=60.0 \mathrm{~km} / \mathrm{h})$ for the legal speed limit for road vehicles, including cars.

Figures 4 and 5 show the speed of each region in detail. For example, it was found that the speed was high on train railways and highways, and was fast along the arterial streets where cars and tracks run. In contrast, in residential areas, the speeds were slow. This was because walking and cycling were the main modes of travel in residential areas. Next, the EBK-Speed maps for April 2019 and April 2020 were compared. The results show that in April 2020, the areas with a slow-cycling speed (1.0-3.0 m/s) decreased, and the areas with a faster-cycling speed $(3.0-8.33 \mathrm{~m} / \mathrm{s})$ increased.

In order to validate the results, the EBK-Speed-Change map was analyzed, as shown in Figure 6. The analysis was done as part of phase 3, as depicted in Figure 2. The data in Figure 4 were subtracted from the raster data of April 2020 EBK-Speed map and the raster data of the April 2019 EBK-Speed map.

Figure 6 shows that the changes in EBK-Speed were related to the types of residential clusters. For example, the change was larger in mountainous areas. However, in the residential area, it was found that the speed decreased along the street but increased inside the residential area. 


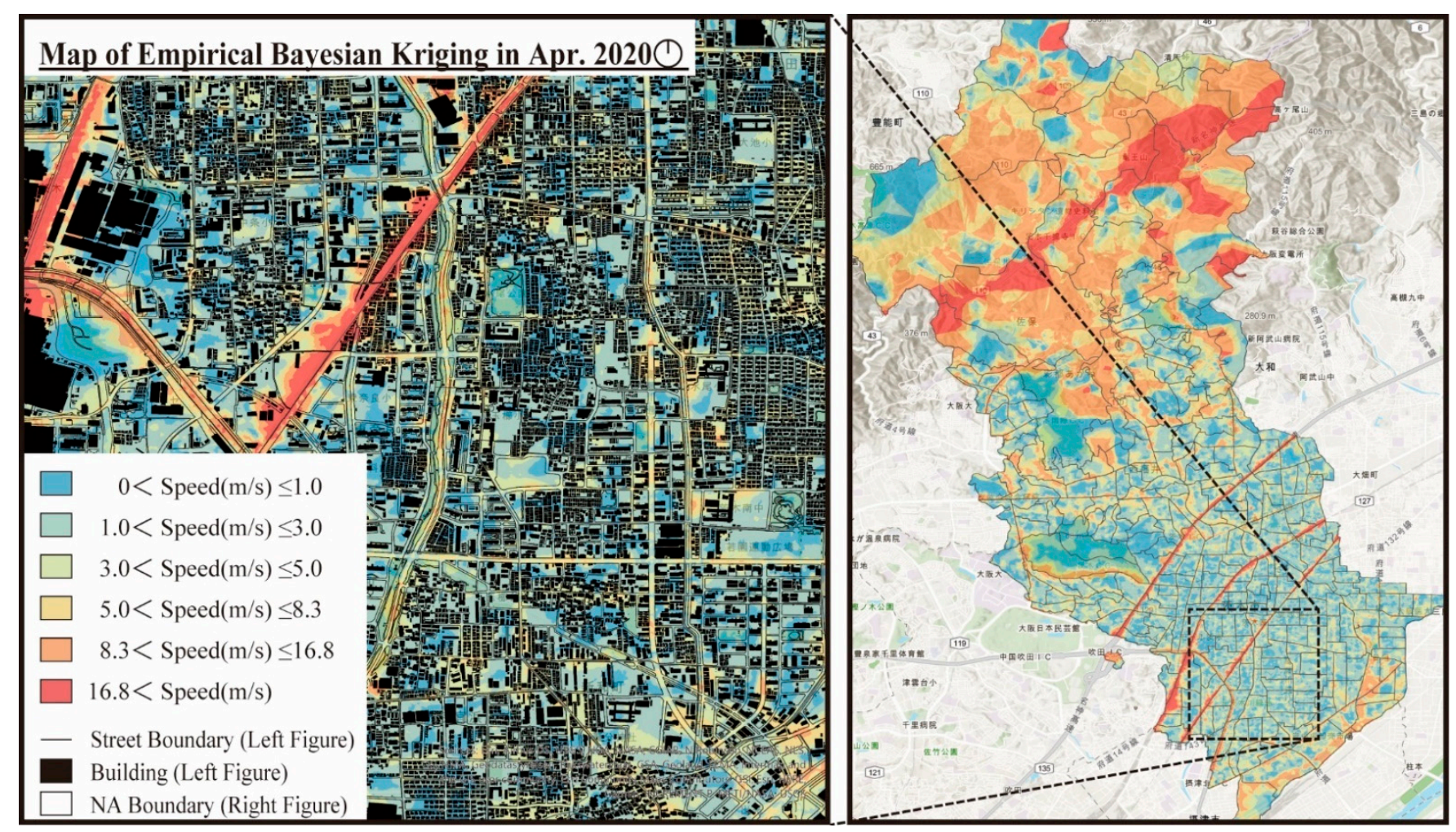

Figure 4. EBK-Speed map of Ibaraki City in April 2020 (drawing only for Ibaraki City).

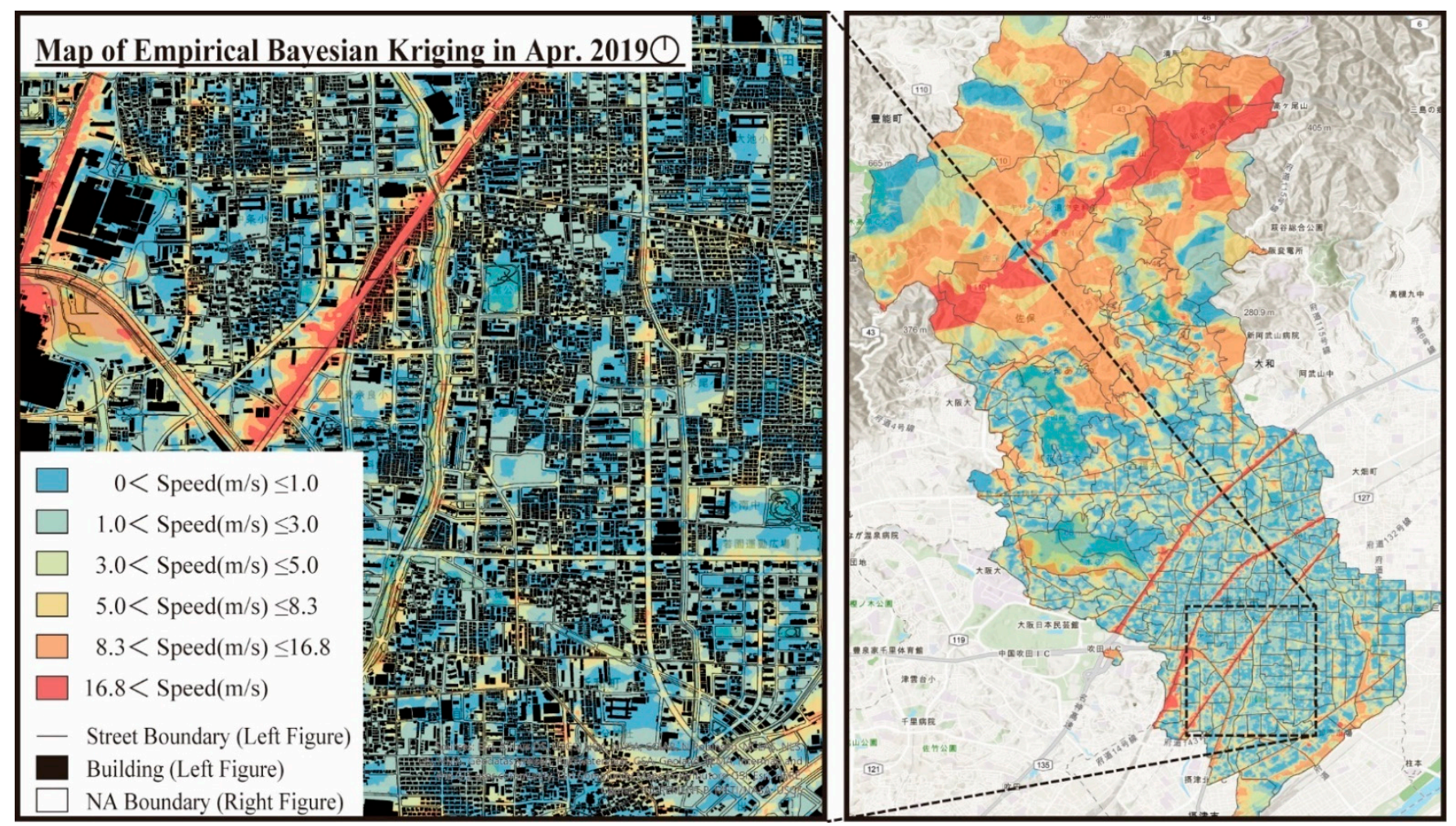

Figure 5. EBK-Speed map of Ibaraki City in April 2019 (drawing only for Ibaraki City). 


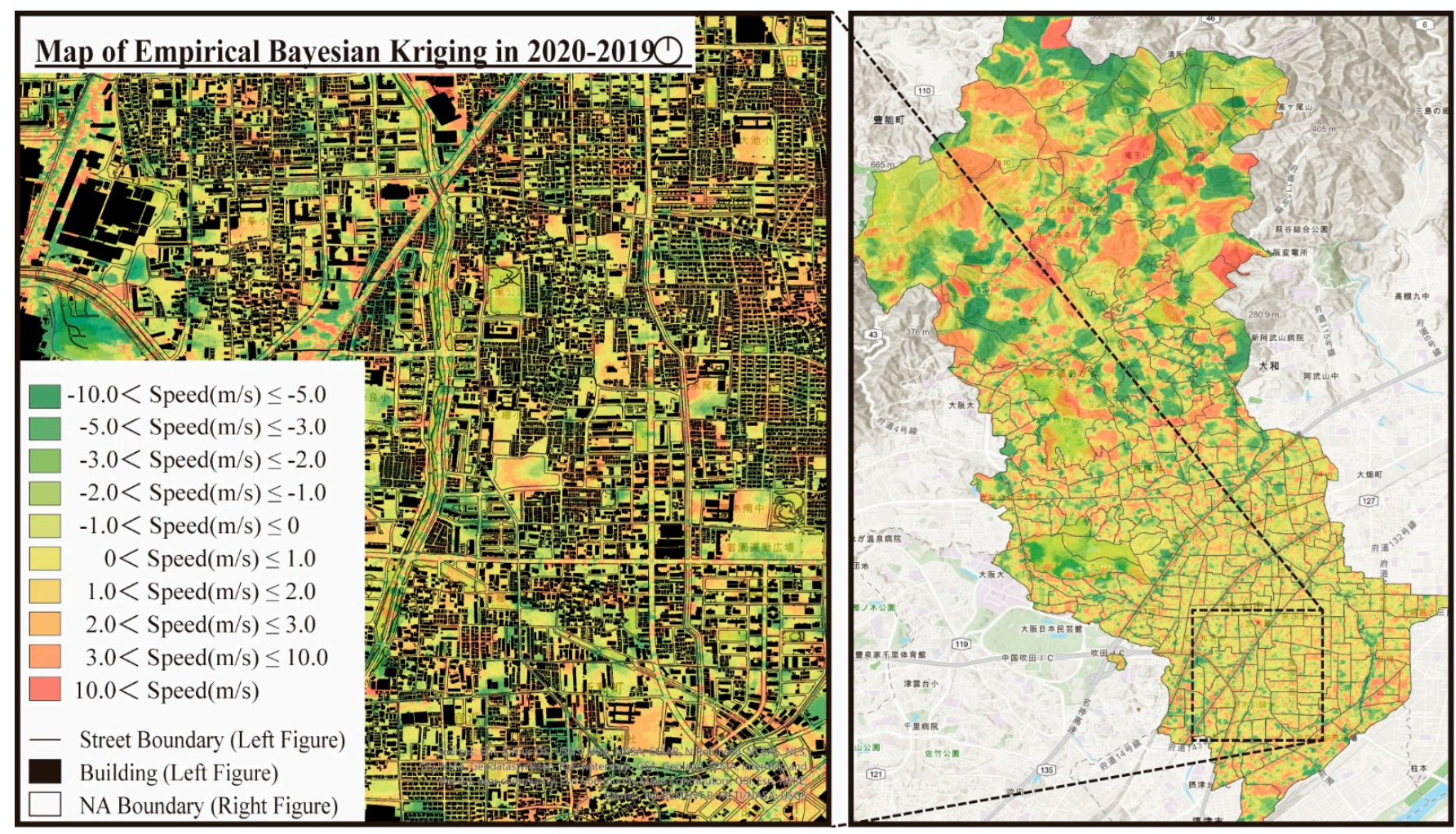

Figure 6. EBK-Change-Speed map of Ibaraki City comparing April 2020 with April 2019 (drawing only for Ibaraki City).

\subsection{EBK-Speed-Change of Each Residential Cluster}

The EBK-Speed data of each NA was analyzed for each residential cluster. The residential clusters were identified using the urban ecological analysis described in Section 2.3. The analysis was done as part of phase 6, as depicted in Figure 2. The results are plotted as a box-plot diagram in Figure 7. As shown in Figure 7, significant differences in the average values of April 2019 and April 2020 were analyzed by the student's $t$-test.

Figure 7 shows six residential clusters whose speed in April 2020 had significantly changed from April 2019: the inner-city, dense, sprawl, mountain, old NT, and rural clusters. Of the six clusters, two decreased significantly in speed, namely, the inner-city and rural clusters. The other four clusters increased significantly in speed.

For these six residential clusters, the median value of the speed of April 2020 was focused on. Figure 7 shows that the median value was a slow-cycling speed $(1.0-3.0 \mathrm{~m} / \mathrm{s})$ in the inner-city, dense, sprawl, old NT, and rural clusters. In contrast, in the mountain cluster, the median value was a slow-car speed $(5.0-8.33 \mathrm{~m} / \mathrm{s})$.

For the six clusters with significant differences, the EBK-Speed-Change data were analyzed for each street width of the residential cluster in Figure 8 . Figure 8 shows the $95 \%$ confidence intervals as error bars. The analysis was done as part of phase 5 , as depicted in Figure 2. Figure 7 shows the error bars for the $95 \%$ confidence interval. Figure 8 shows the streets, with significant differences in the average values of each residential cluster analyzed by Tukey's HSD test of the one-way ANOVA.

The results are discussed for each residential cluster. Figure 8 shows that the streets where the average speed changed significantly for each cluster were the narrow streets ( $\mathrm{W}<3 \mathrm{~m}$ ), the neighborhood streets $(3 \mathrm{~m} \leq \mathrm{W}<5.5 \mathrm{~m})$, and the main neighborhood streets $(5.5 \mathrm{~m} \leq \mathrm{W}<13 \mathrm{~m})$. However, although there was a change in speed between the arterial streets $(13 \mathrm{~m} \leq \mathrm{W}<19.5 \mathrm{~m})$ and the main arterial streets $(19.5 \mathrm{~m} \leq \mathrm{W})$, there was no statistically significant difference between the clusters. For the narrow streets, the speed decreased significantly in the inner-city cluster, while it significantly increased in the dense, sprawl, mountain, and old NT clusters. Among them, the speed increased significantly in 
the mountain cluster. For the neighborhood streets, the speed significantly decreased in the inner-city cluster, while it significantly increased in the dense, sprawl, mountain, and old NT clusters. Finally, for the main neighborhood street, the speed significantly decreased in the inner-city cluster, while it significantly increased in the sprawl, mountain, and old NT clusters. The results suggest that, on narrower streets such as the neighborhood streets, the speed significantly decreased in the inner-city cluster but significantly increased in the dense, sprawl, mountain, and old NT clusters.

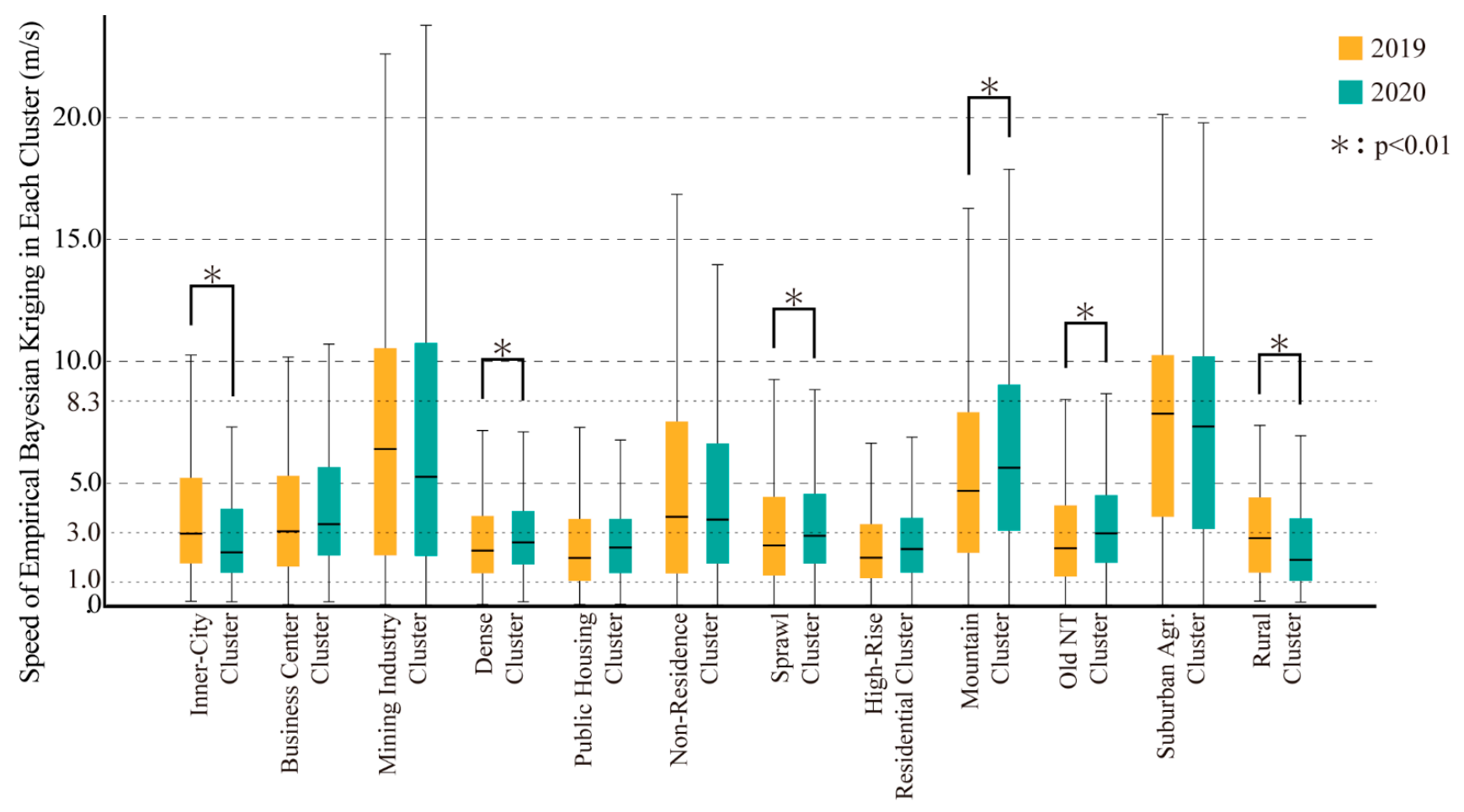

Figure 7. EBK-Speed of each residential cluster in April 2019 and April 2020.

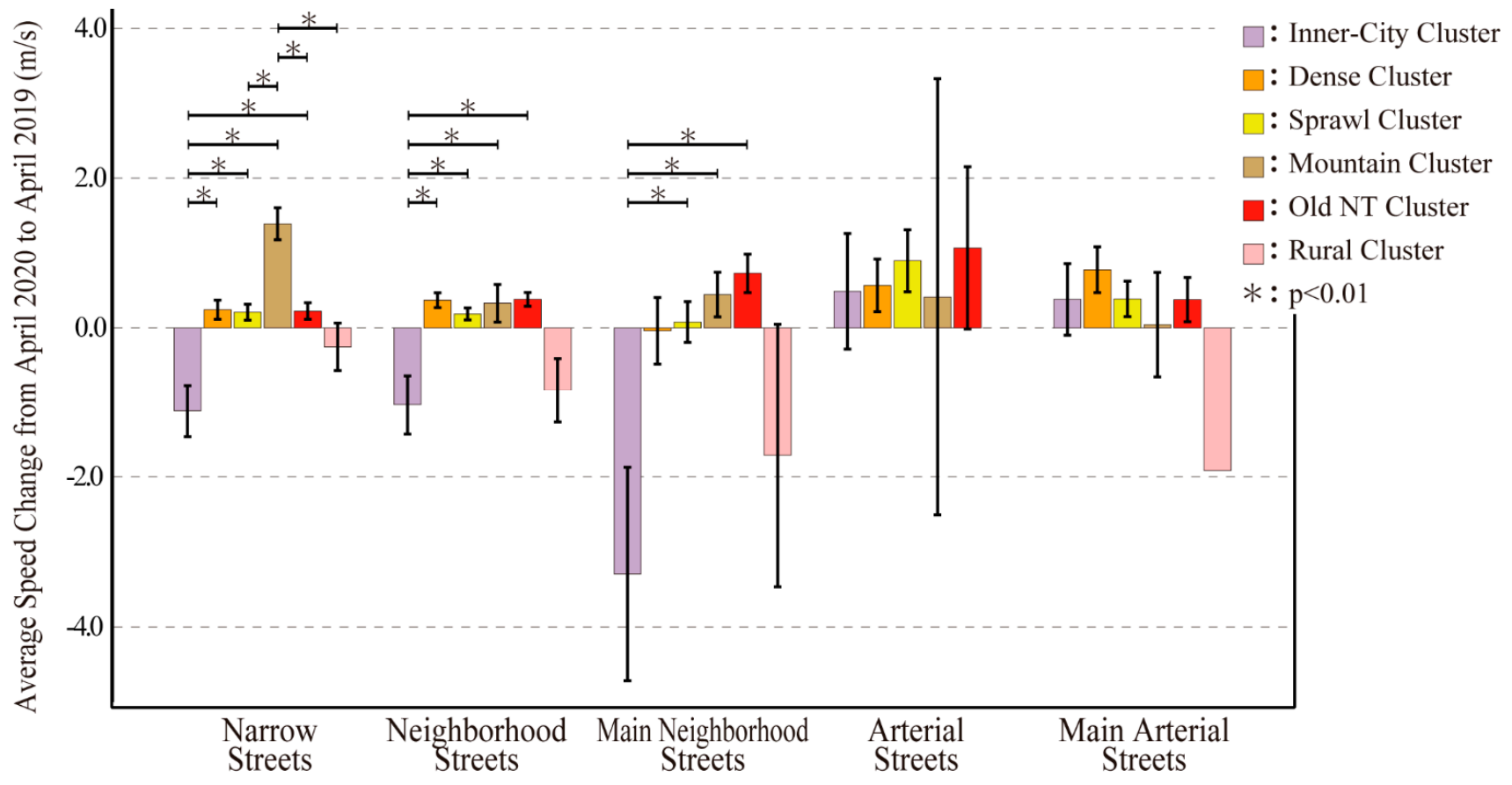

Figure 8. EBK-Speed-Change of the streets in each residential cluster. 


\subsection{Mobility Change of Each Residential Cluster}

Finally, the validity of the changes was verified using the estimated transportation means of the LH data. The estimated transportation means were the data that were independently estimated by the Agoop Corporation, which provided the LH data. Since only about $9 \%$ of the total number of logs was estimated, the data were used to validate the results in Section 3.2. Therefore, the estimated transportation means of the LH data in each NA for April 2019 and April 2020 were analyzed for each residential cluster. The $\log$ types of the estimated transportation means were walking, cycling, train, and car. The stop logs with the estimated transportation means were not analyzed. This section provides the analysis results for the inner-city, dense, sprawl, mountain, old NT, and rural clusters. Since the total number of logs differed between April 2019 (307,810 logs) and April $2020(324,986 \operatorname{logs})$, this section provides the results of the analysis of the amounts of LH data for each estimated transportation. The means of April 2019 and April 2020 were divided by the total number of logs of April 2019 and April 2020. Figure 9 shows the average values of the transportation means of the NA between April 2019 and April 2020 for each residential cluster. As shown in Figure 9, the residential clusters with significant differences in the average values of transportation mean in 2019 and 2020 were analyzed by the student's $t$-test.

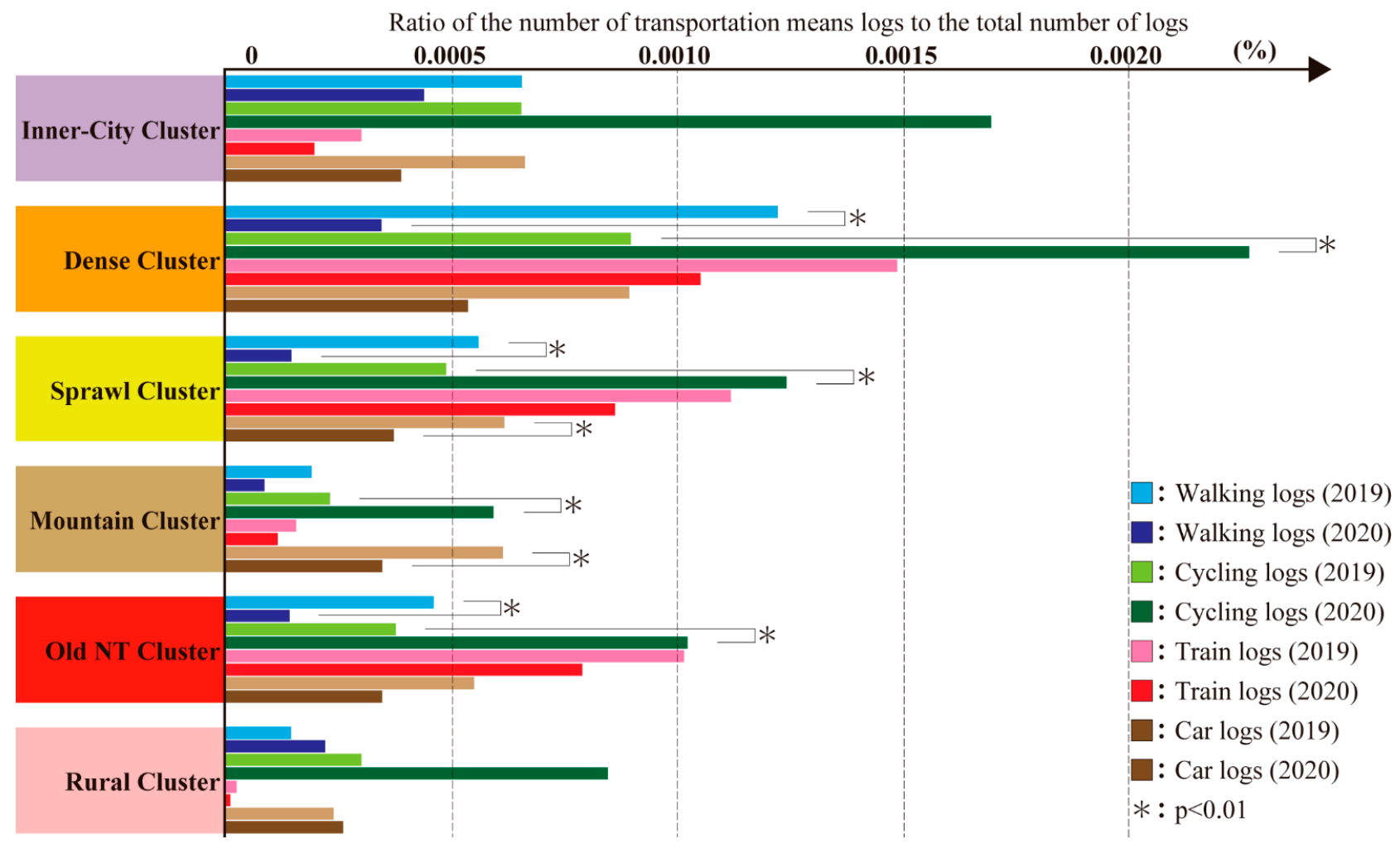

Figure 9. Mobility changes in each residential cluster.

The results are discussed for each of the estimated transportation means. Figure 9 shows that the number of walking logs decreased, except for the rural cluster. The number of walking logs significantly decreased in the dense, sprawl, and old NT clusters. In contrast, Figure 9 shows that the number of cycling logs increased in all the residential clusters. In the dense, sprawl, mountain, and old NT clusters, the number of cycling logs increased significantly. Next, Figure 9 shows that the number of train logs decreased in all residential clusters. Of these, there were no residential clusters in which the number of train logs changed significantly. Finally, Figure 9 shows that the number of car logs decreased, 
except for the rural cluster. Of these, the number of car logs significantly decreased in the sprawl and mountain clusters.

\section{Discussion}

This study identified the streets where traffic behavior changed during the COVID-19 pandemic. The results were calculated via EBK using the LH data and were analyzed for each residential cluster. The results are summarized in Table 1. Specifically, during the COVID-19 pandemic, the speed significantly decreased in the inner-city and rural clusters. In the inner-city cluster, the speed decreased on the narrow, neighborhood, and main neighborhood streets. However, in the rural cluster, the speed decreased on the narrow streets. In contrast, during the COVID-19 pandemic, the speed significantly increased in the dense, sprawl, mountain, and old NT clusters. In the dense cluster, it was found that the speed increased significantly on the narrow and neighborhood streets, with a significant decrease in walking, but a significant increase in cycling. In the sprawl cluster, it was found that the speed increased significantly on the narrow, neighborhood, and main neighborhood streets, with a significant decrease in walking and driving but a significant increase in cycling. In the mountain cluster, the speed increased significantly on the narrow, neighborhood, and main neighborhood streets, with a significant decrease in driving but a significant increase in cycling. Finally, in the old NT cluster, the speed increased significantly on the narrow, neighborhood, and main neighborhood streets, with a significant decrease in walking but a significant increase in cycling.

Table 1. Human mobility changes in each residential cluster.

\begin{tabular}{cccc}
\hline Cluster & $\begin{array}{c}\text { Speed Change } \\
\text { (Figure 7) }\end{array}$ & $\begin{array}{c}\text { Streets } \\
\text { (Figure 8) }\end{array}$ & $\begin{array}{c}\text { Transportation Means } \\
\text { (Figure 9) }\end{array}$ \\
\hline Inner-city cluster & Decreased & $\begin{array}{c}\text { Narrow streets (decrease in speed) } \\
\text { Neighborhood streets (decrease in speed) } \\
\text { Main neighborhood streets (decrease in speed) }\end{array}$ & Walking (decrease in logs) \\
Cycling (increase in logs)
\end{tabular}

The results suggest that the number of people who rode bicycles increased during the state of emergency was declared as part of the "new normal" lifestyle. Since the LH data do not include personal information, such as age and addresses, it will be necessary to clarify the characteristics of those who switched to cycling in future research. However, there are three possible reasons for the increase in cycling. First, people avoided using public transport. The number of scheduled buses was reduced due to the risk of SARS-CoV-2 infection in public transportation [42]. Second, people exercised by cycling. During the COVID-19 pandemic in Japan, it was reported that more and more people traveled by bicycle to alleviate the lack of exercise [43]. For example, Ibaraki City promoted cycling 
as a leisure activity in mountainous areas [44]. The third reason was the increase in fooddelivery services. During the COVID-19 pandemic, the number of services such as Uber Eats that deliver restaurant meals by bicycle increased [45]. In Ibaraki City, there was a local service called "IBAR EATS" in operation [46]. For these reasons, it is thought that the number of people cycling increased rapidly.

\section{Conclusions}

In the future, walkable streets need to be designed according to each residential cluster for the post-COVID-19 pandemic era. For example, in the dense, sprawl, and old NT clusters, some car lanes need to be converted to bike lanes on the main neighborhood streets $(5.5 \mathrm{~m} \leq \mathrm{W}<13 \mathrm{~m})$. The National Association of City Transportation Officials (NACTO) [27] proposed that streets be redesigned during the COVID-19 pandemic. For example, there are more and more cases where pop-up bike lanes are effectively used to improve cycling networks (e.g., [47]). In the short term, pop-up bike lanes are effective in improving cycling networks. In the long term, in addition to the construction of bike lanes, comprehensive measures such as cycling parking, media campaigns, and cycling skill training are adequate for the cycling networks. Chapman et al. [48] pointed out that the cost-effectiveness of the comprehensive measures is 11.0. Therefore, in Japan as well, it will be include effective comprehensive measures such as the construction of bike lanes, cycling parking, and cycling skill training in the long term. However, in Japan, few municipalities have improved their cycling networks. This is because many bicycle lanes cross many municipalities, making it difficult for each municipality to develop them independently. Therefore, it is hoped that the central government will promote the construction of bike lanes to local municipalities as infrastructure development projects for the COVID-19 pandemic. Figure 10 shows a cycling network in Ibaraki city that author H.K. photographed in April 2021. In Ibaraki, the police department reported that the number of injuries in traffic accidents related to cycling increased, from 235 people in JanuaryDecember 2019 to 259 people in January-December 2020 [49]. An increasing number of accidents was also reported in New York City [50]. An enriched living environment can be achieved by designing neighborhoods where people can ride bicycles safely. It also enables older adults to walk safely on pedestrian paths because bicycles will no longer ride on the pedestrian path. Paris [24] proposed 15-min cities, and Portland [51] proposed 20-min neighborhoods. Japan, with its aging society, also needs to redesign its cities strategically. Walkable neighborhoods, which are easy to traverse by walking or cycling, will not only improve the health of older adults, but will also create cities with low environmental footprints. It is expected to contribute to Goal 11 of the Sustainable Development Goals (SDGs): "Make cities and human settlements inclusive, safe, resilient and sustainable." The COVID-19 pandemic has indeed accelerated the enrichment of neighborhood environments.

In April 2021, the government declared a state of emergency in Osaka Prefecture for the third time. Besides, the number of new variants of SARS-CoV-2 has been increasing. Therefore, it is expected that we will continue to live in coexistence with the virus during the pandemic for some years. The limitation of this research is that we only compare April 2019 and April 2020. This limitation means that this study only clarified that the number of bicycles increased during the COVID-19 pandemic. In addition, this study cannot analyze the data after the COVID-19 pandemic. In other words, we cannot deny the possibility of a very specific result during the state of emergency in Ibaraki City. Research on the design of walkable streets needs to be continued in the future, increasing the research periods after the state of emergency. 

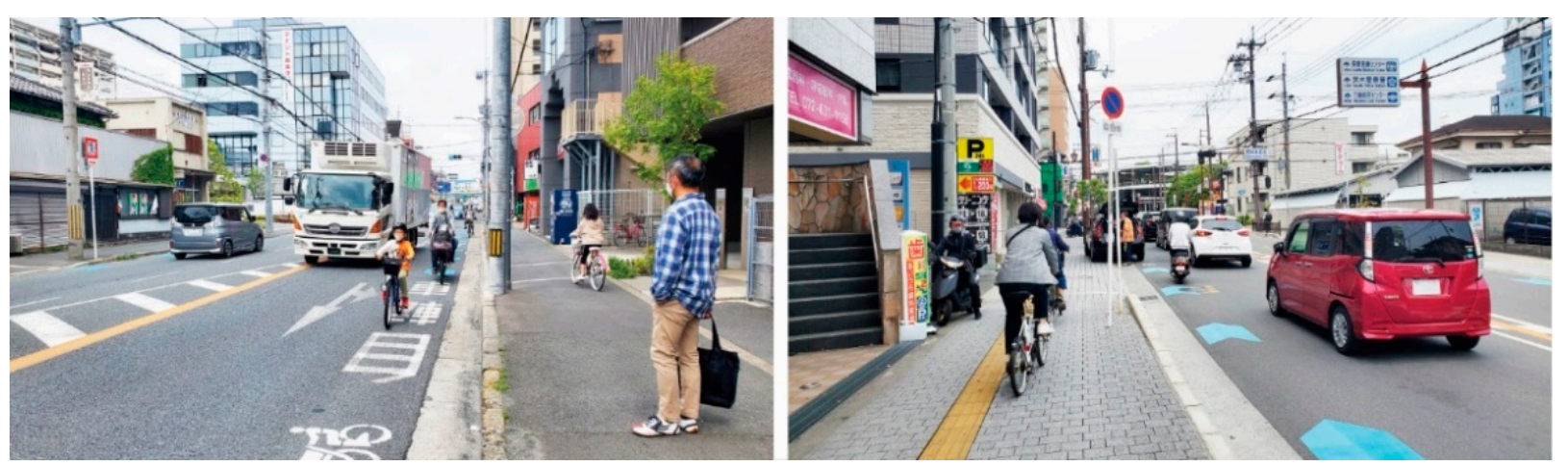

Figure 10. Images of the cycling network in Ibaraki City.

Author Contributions: Conceptualization, H.K.; methodology, H.K.; software, H.K.; validation, H.K. and D.M.; formal analysis, H.K.; investigation, H.K.; resources, H.K.; data curation, H.K.; writingoriginal draft preparation, H.K.; writing—review and editing, H.K. and D.M.; visualization, H.K.; supervision, H.K.; project administration, H.K.; funding acquisition, H.K. All authors have read and agreed to the published version of the manuscript.

Funding: This research was funded by the JSPS KAKENHI (grant number 21K14318).

Institutional Review Board Statement: The protocol of this study was approved by the Agoop Corporation, which provides anonymized LH data.

Informed Consent Statement: Informed consent was obtained from all subjects who install particular applications, based on the type of data to be collected, purpose of use, provision to third parties, and privacy policy. Additionally, the subjects can stop sending the GPS location data at any time by changing their mobile phones' settings.

Data Availability Statement: The data of this study cannot be shared publicly due to mobile phone users' confidentiality. GPS location history panel data are available to researchers and governments through agreements with the Agoop Corporation. By establishing contacts with the corporation, various stakeholders can access and utilize LH data for research purposes according to the "Guidelines for the Use of Device Location Data" to protect the privacy of users' GPS location history.

Acknowledgments: The authors are deeply grateful for the support of the Urban Development Department of the Ibaraki City Government (Local Government in the Osaka Metropolitan Area). This study was undertaken using data provided by the Conservation GIS Consortium Japan (Conservation GIS Consortium Japan. Available online: http:/ / cgisj.jp (accessed on 1 July 2021)).

Conflicts of Interest: The authors declare no conflict of interest.

\section{Appendix A}

Urban ecological analysis analyzes spatial patterns via an inductive method using a wide range of statistical data [33]. The analysis consisted of five steps.

First, the standardization of the 53 indicators used for the NA scale, the 2015 Japanese census was analyzed [16,34]. The 53 indicators were census data such as "population under 15 years old" and "households who live in detached houses" (Appendix A). Next, the standardized composition ratio $R_{x}^{k}$ was calculated by standardizing each indicator's data, which is the distribution of data among the 53 indicators using Equation (A1):

$$
R_{x}^{k}=\frac{X_{x i}^{k}-X_{x \min }}{X_{x \max }-X_{x \min }},
$$

where $X_{x i}^{k}$ is the number of NA $i$ for indicator $x$ in the residential area $k, X_{x m i n}$ is the minimum value of NA $i$ for indicator $x$, and $X_{x \max }$ is the maximum value of NA $i$ for indicator $x$. 
Third, the principal component was analyzed using $R_{x}^{k}$. The social survey data were deemed reliable because the Cronbach's $\alpha$ coefficient of the principal component analysis was 0.985 . Cronbach's alpha is the measure of reliability and internal consistency of data. Fourth, using the Kaiser criterion, seven principal components were extracted. The obtained data were deemed reliable because the total variable amount of these seven principal components was $78.8 \%$. Finally, using their seven principal component scores, residential clusters were categorized via hierarchical cluster analysis.

In addition to the urban ecological analysis, this study analyzed the urbanized area ratio and the average distance from the center. The urbanized area ratio was analyzed using the National Land Information Download Service [52]. The urbanized area ratio is the ratio of the residential areas that were designated as urbanized areas by their local governments. The average distance from the center of the metropolitan area, Umeda in Osaka city, Karasuma in Kyoto city, and Sannomiya Station in Kobe City was then calculated. Then, by analyzing the $\mathrm{R}_{\mathrm{ki}}$, urbanized area ratio and the average distance from the center of each indicator for each residential cluster, each cluster's name was determined (Table A1). Finally, the cluster classification was verified by analyzing the average land use area $\left(\mathrm{m}^{2}\right)$ by the data of the Numerical Map 5000 in Japan [53] (Table A2), and by looking at a part of the sites in Ibaraki City (Figure A1).
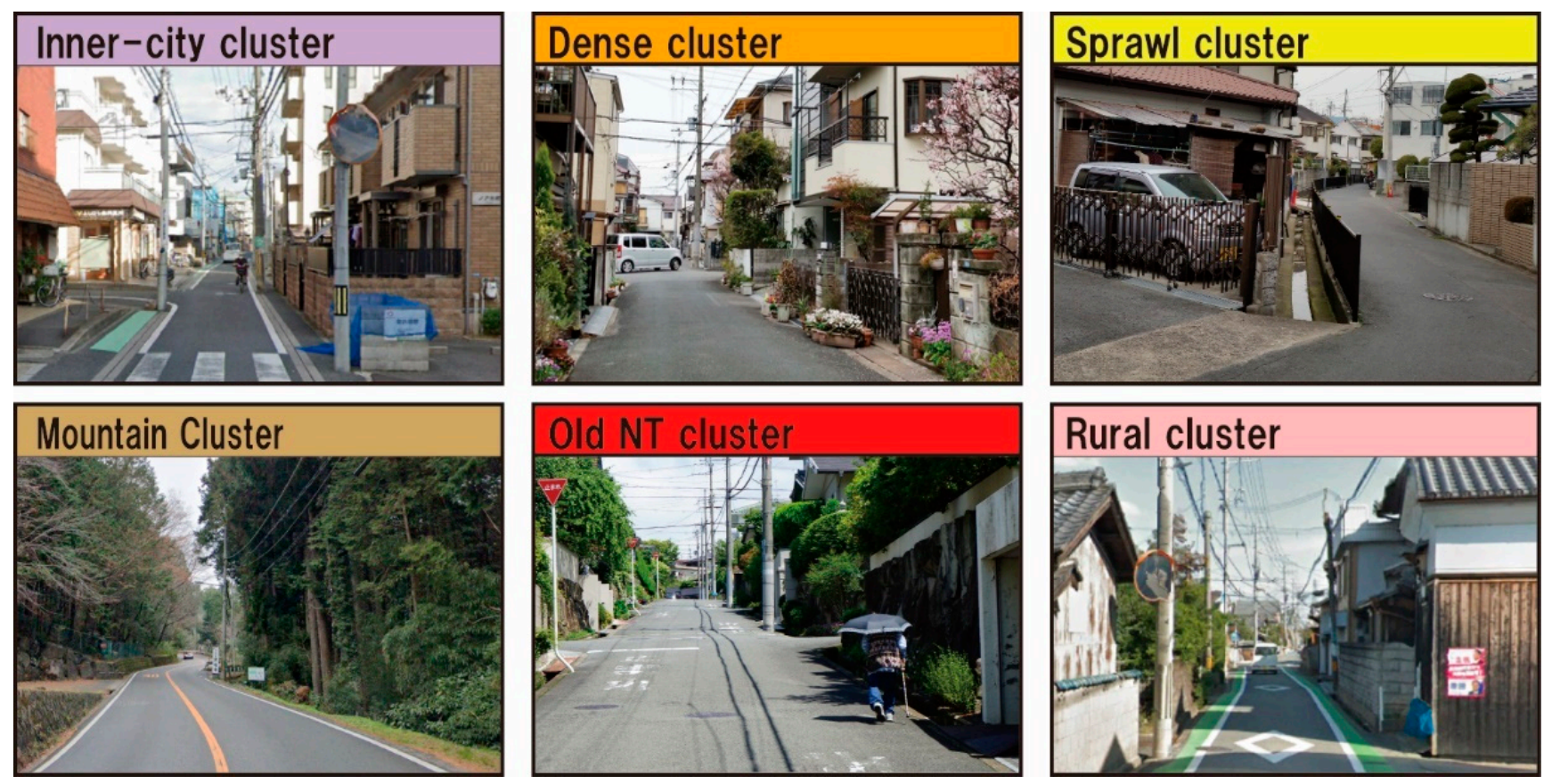

Figure A1. Images of residential clusters that this study analyzed. 
Table A1. The $\mathrm{R}_{\mathrm{ki}}$ of each indicator for each residential cluster (Table A1 features the same data as Table A.1 in Kato [4]).

\begin{tabular}{|c|c|c|c|c|c|c|c|c|c|c|c|c|c|}
\hline Heading & 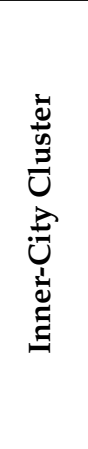 & 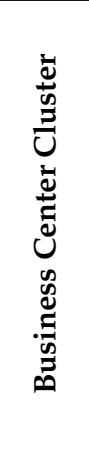 & 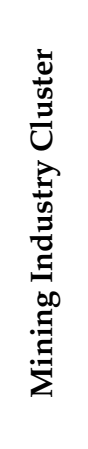 & 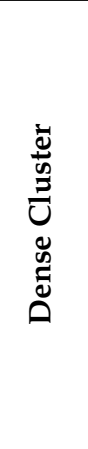 & 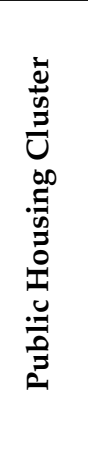 & 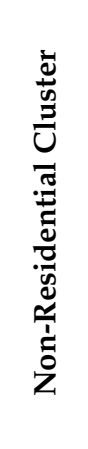 & 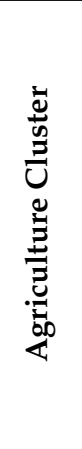 & 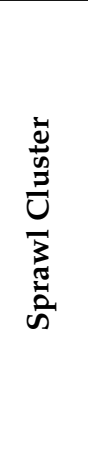 & 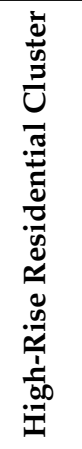 & 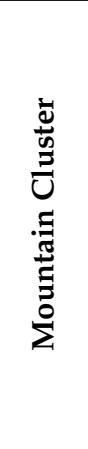 & 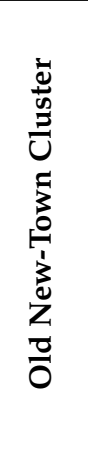 & 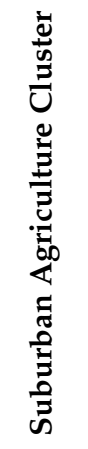 & 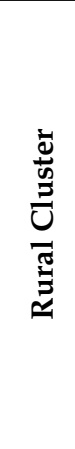 \\
\hline Number of residential areas in the cluster $(\mathrm{N})$ & 1937 & 5472 & 728 & 672 & 889 & 7403 & 297 & 4998 & 628 & 7251 & 2546 & 2914 & 1033 \\
\hline Urbanized area ratio $(\%)$ & 84.5 & 86.2 & 45.1 & 77.1 & 72.4 & 55.2 & 23.6 & 66.2 & 61.8 & 40.7 & 59.1 & 21.3 & 24.9 \\
\hline Average distance from the center $(\mathrm{km})$ & 19.3 & 34.5 & 59.9 & 31.2 & 26.7 & 43.9 & 71.6 & 38.2 & 25.9 & 56.1 & 26.7 & 63.1 & 52.1 \\
\hline Population under 15 years old (\%) & 0.06 & 0.01 & 0.03 & 0.06 & 0.05 & 0.00 & 0.04 & 0.02 & 0.09 & 0.01 & 0.03 & 0.01 & 0.10 \\
\hline Population between 16 and 64 years old (\%) & 0.09 & 0.02 & 0.04 & 0.09 & 0.08 & 0.00 & 0.06 & 0.03 & 0.12 & 0.01 & 0.05 & 0.02 & 0.14 \\
\hline Population over 65 years old $(\%)$ & 0.10 & 0.02 & 0.04 & 0.07 & 0.12 & 0.00 & 0.09 & 0.04 & 0.11 & 0.01 & 0.05 & 0.03 & 0.15 \\
\hline Population of foreigners $(\%)$ & 0.09 & 0.02 & 0.02 & 0.04 & 0.07 & 0.00 & 0.01 & 0.02 & 0.03 & 0.00 & 0.01 & 0.00 & 0.05 \\
\hline Population who live in public housing (\%) & 0.01 & 0.00 & 0.00 & 0.01 & 0.12 & 0.00 & 0.01 & 0.00 & 0.01 & 0.00 & 0.00 & 0.00 & 0.01 \\
\hline Population who live in private rented houses (\%) & 0.10 & 0.02 & 0.02 & 0.10 & 0.02 & 0.00 & 0.02 & 0.03 & 0.05 & 0.00 & 0.02 & 0.00 & 0.07 \\
\hline Population who live in houses for employees (\%) & 0.02 & 0.00 & 0.01 & 0.08 & 0.01 & 0.00 & 0.01 & 0.01 & 0.02 & 0.00 & 0.01 & 0.00 & 0.02 \\
\hline Population who live in shared houses (\%) & 0.08 & 0.02 & 0.02 & 0.05 & 0.03 & 0.00 & 0.04 & 0.03 & 0.06 & 0.01 & 0.03 & 0.01 & 0.09 \\
\hline Households who live outside of houses (\%) & 0.00 & 0.00 & 0.00 & 0.03 & 0.00 & 0.00 & 0.00 & 0.00 & 0.00 & 0.00 & 0.00 & 0.00 & 0.01 \\
\hline Households who live in detached houses (\%) & 0.07 & 0.02 & 0.05 & 0.05 & 0.03 & 0.00 & 0.10 & 0.04 & 0.09 & 0.02 & 0.06 & 0.03 & 0.19 \\
\hline Households who live in traditional nagaya houses (\%) & 0.08 & 0.01 & 0.02 & 0.03 & 0.02 & 0.00 & 0.02 & 0.03 & 0.02 & 0.00 & 0.01 & 0.00 & 0.07 \\
\hline Households who live in apartments (\%) & 0.08 & 0.02 & 0.02 & 0.08 & 0.10 & 0.00 & 0.01 & 0.02 & 0.08 & 0.00 & 0.02 & 0.00 & 0.04 \\
\hline Households who live in 1- or 2-storey buildings (\%) & 0.05 & 0.02 & 0.04 & 0.07 & 0.02 & 0.00 & 0.04 & 0.05 & 0.05 & 0.00 & 0.03 & 0.01 & 0.16 \\
\hline Households who live in 3- to 5 -storey buildings (\%) & 0.05 & 0.01 & 0.01 & 0.07 & 0.11 & 0.00 & 0.01 & 0.02 & 0.05 & 0.00 & 0.01 & 0.00 & 0.03 \\
\hline Households who live in 6- to 10-storey buildings (\%) & 0.06 & 0.01 & 0.01 & 0.06 & 0.04 & 0.00 & 0.00 & 0.01 & 0.05 & 0.00 & 0.01 & 0.00 & 0.02 \\
\hline Households who live in 11 (or more)-storey buildings (\%) & 0.03 & 0.00 & 0.00 & 0.02 & 0.04 & 0.00 & 0.00 & 0.00 & 0.04 & 0.00 & 0.01 & 0.00 & 0.00 \\
\hline Population who work in agriculture and forestry (\%) & 0.00 & 0.00 & 0.01 & 0.00 & 0.00 & 0.00 & 0.13 & 0.00 & 0.01 & 0.01 & 0.00 & 0.03 & 0.03 \\
\hline Population who work in a fishery $(\%)$ & 0.00 & 0.00 & 0.01 & 0.00 & 0.00 & 0.00 & 0.04 & 0.00 & 0.00 & 0.00 & 0.00 & 0.00 & 0.00 \\
\hline Population who work in the mining industry (\%) & 0.00 & 0.00 & 0.09 & 0.00 & 0.00 & 0.00 & 0.05 & 0.00 & 0.00 & 0.00 & 0.00 & 0.00 & 0.01 \\
\hline Population who work in the construction industry (\%) & 0.08 & 0.01 & 0.04 & 0.06 & 0.07 & 0.00 & 0.07 & 0.04 & 0.09 & 0.01 & 0.04 & 0.02 & 0.15 \\
\hline Population who work in the manufacturing industry (\%) & 0.05 & 0.01 & 0.03 & 0.07 & 0.05 & 0.00 & 0.05 & 0.03 & 0.08 & 0.01 & 0.03 & 0.02 & 0.12 \\
\hline
\end{tabular}


Table A1. Cont.

\begin{tabular}{|c|c|c|c|c|c|c|c|c|c|c|c|c|c|}
\hline Heading & 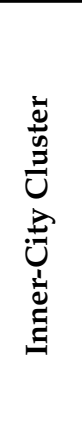 & 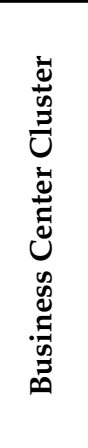 & 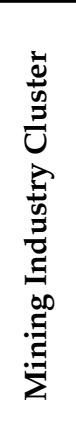 & 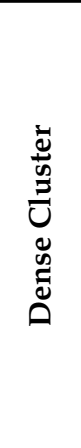 & 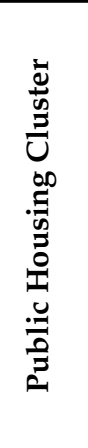 & 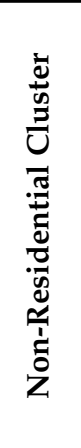 & 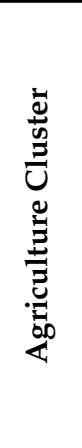 & 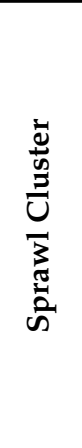 & 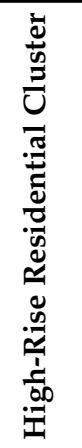 & 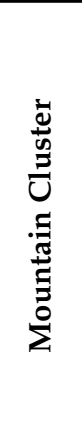 & 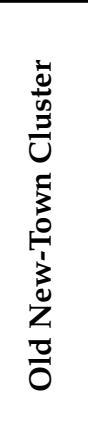 & 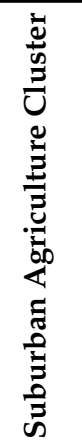 & 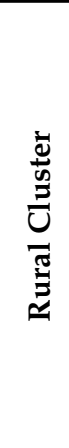 \\
\hline $\begin{array}{c}\text { Population who work in the electricity, gas, and water supply } \\
\text { industries (\%) }\end{array}$ & 0.01 & 0.00 & 0.01 & 0.02 & 0.01 & 0.00 & 0.01 & 0.01 & 0.03 & 0.00 & 0.01 & 0.00 & 0.03 \\
\hline Population who work in the information industry (\%) & 0.08 & 0.01 & 0.02 & 0.08 & 0.04 & 0.00 & 0.01 & 0.02 & 0.12 & 0.00 & 0.04 & 0.00 & 0.06 \\
\hline Population who work in the transport industry (\%) & 0.08 & 0.02 & 0.03 & 0.07 & 0.10 & 0.00 & 0.05 & 0.04 & 0.09 & 0.01 & 0.04 & 0.02 & 0.14 \\
\hline Population who work in the retail industry $(\%)$ & 0.09 & 0.02 & 0.03 & 0.08 & 0.07 & 0.00 & 0.06 & 0.03 & 0.12 & 0.01 & 0.04 & 0.02 & 0.13 \\
\hline Population who work in the financial industry $(\%)$ & 0.06 & 0.01 & 0.02 & 0.08 & 0.04 & 0.00 & 0.03 & 0.02 & 0.12 & 0.00 & 0.04 & 0.01 & 0.08 \\
\hline Population who work in the real estate business (\%) & 0.09 & 0.02 & 0.03 & 0.08 & 0.06 & 0.00 & 0.02 & 0.03 & 0.12 & 0.01 & 0.04 & 0.01 & 0.08 \\
\hline Population who work in the entertainment industry $(\%)$ & 0.06 & 0.01 & 0.02 & 0.05 & 0.05 & 0.00 & 0.04 & 0.02 & 0.07 & 0.01 & 0.03 & 0.01 & 0.09 \\
\hline Population who work in education $(\%)$ & 0.06 & 0.02 & 0.03 & 0.08 & 0.04 & 0.00 & 0.05 & 0.02 & 0.13 & 0.01 & 0.05 & 0.02 & 0.10 \\
\hline Population who work in the medical/welfare industry (\%) & 0.07 & 0.02 & 0.03 & 0.07 & 0.07 & 0.00 & 0.06 & 0.03 & 0.11 & 0.01 & 0.04 & 0.02 & 0.13 \\
\hline Population who work in a joint service industry $(\%)$ & 0.05 & 0.01 & 0.05 & 0.06 & 0.05 & 0.00 & 0.18 & 0.03 & 0.09 & 0.02 & 0.04 & 0.05 & 0.18 \\
\hline Population who work in another service industry (\%) & 0.09 & 0.02 & 0.04 & 0.08 & 0.10 & 0.00 & 0.06 & 0.04 & 0.11 & 0.01 & 0.04 & 0.02 & 0.14 \\
\hline Population who work as civil servants (\%) & 0.02 & 0.00 & 0.01 & 0.05 & 0.01 & 0.00 & 0.02 & 0.01 & 0.04 & 0.00 & 0.01 & 0.01 & 0.04 \\
\hline Population who work at home $(\%)$ & 0.08 & 0.02 & 0.04 & 0.06 & 0.04 & 0.00 & 0.18 & 0.03 & 0.07 & 0.01 & 0.03 & 0.05 & 0.13 \\
\hline Population who work in their own city (\%) & 0.06 & 0.01 & 0.04 & 0.07 & 0.06 & 0.00 & 0.07 & 0.03 & 0.07 & 0.01 & 0.03 & 0.02 & 0.14 \\
\hline Population who work in other cities $(\%)$ & 0.07 & 0.01 & 0.03 & 0.07 & 0.06 & 0.00 & 0.04 & 0.02 & 0.11 & 0.01 & 0.04 & 0.01 & 0.10 \\
\hline Population who work in other wards of their own cities (\%) & 0.07 & 0.01 & 0.01 & 0.01 & 0.03 & 0.00 & 0.00 & 0.00 & 0.01 & 0.00 & 0.00 & 0.00 & 0.00 \\
\hline Population who work in other cities of their own prefectures (\%) & 0.03 & 0.00 & 0.02 & 0.07 & 0.05 & 0.00 & 0.05 & 0.03 & 0.09 & 0.01 & 0.04 & 0.01 & 0.12 \\
\hline Population who work in other prefectures $(\%)$ & 0.03 & 0.01 & 0.02 & 0.07 & 0.03 & 0.00 & 0.01 & 0.01 & 0.15 & 0.00 & 0.05 & 0.01 & 0.05 \\
\hline Population who go to school in their own city (\%) & 0.04 & 0.01 & 0.02 & 0.06 & 0.04 & 0.00 & 0.04 & 0.02 & 0.07 & 0.01 & 0.03 & 0.01 & 0.09 \\
\hline Population who go to school in other cities $(\%)$ & 0.07 & 0.01 & 0.03 & 0.06 & 0.06 & 0.00 & 0.04 & 0.03 & 0.14 & 0.01 & 0.05 & 0.01 & 0.11 \\
\hline Population who go to school in other wards of their own cities (\%) & 0.07 & 0.02 & 0.01 & 0.01 & 0.03 & 0.00 & 0.00 & 0.00 & 0.01 & 0.00 & 0.00 & 0.00 & 0.00 \\
\hline Population who go to school in other cities of their own prefectures (\%) & 0.04 & 0.01 & 0.03 & 0.06 & 0.06 & 0.00 & 0.06 & 0.03 & 0.13 & 0.01 & 0.05 & 0.02 & 0.13 \\
\hline Population who go to school in other prefectures $(\%)$ & 0.04 & 0.01 & 0.02 & 0.06 & 0.03 & 0.00 & 0.03 & 0.02 & 0.16 & 0.01 & 0.05 & 0.01 & 0.08 \\
\hline
\end{tabular}


Table A1. Cont.

\begin{tabular}{|c|c|c|c|c|c|c|c|c|c|c|c|c|c|}
\hline Heading & 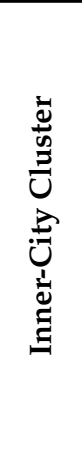 & 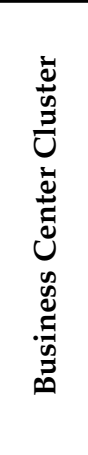 & 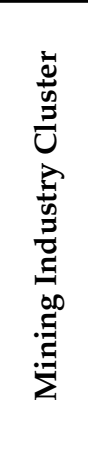 & 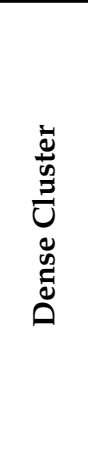 & 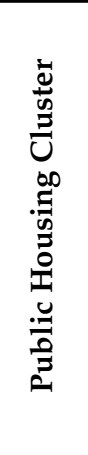 & 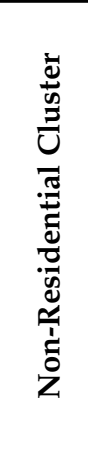 & 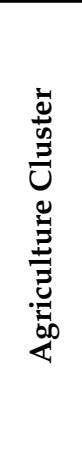 & 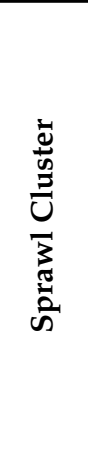 & 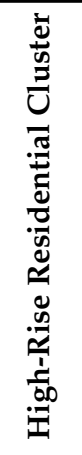 & 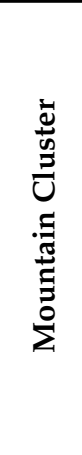 & 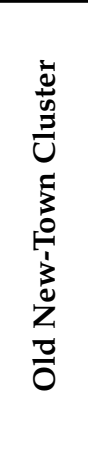 & 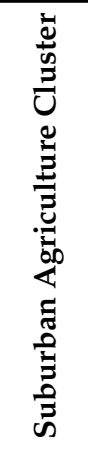 & 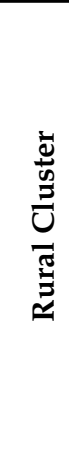 \\
\hline Population who have lived in the area since birth (\%) & 0.07 & 0.02 & 0.05 & 0.06 & 0.05 & 0.00 & 0.13 & 0.04 & 0.10 & 0.02 & 0.04 & 0.05 & 0.17 \\
\hline Population who have lived in the area for 1 year $(\%)$ & 0.06 & 0.02 & 0.02 & 0.10 & 0.05 & 0.00 & 0.03 & 0.03 & 0.07 & 0.00 & 0.03 & 0.01 & 0.08 \\
\hline Population who have lived in the area for the past 5 years (\%) & 0.06 & 0.01 & 0.02 & 0.08 & 0.06 & 0.00 & 0.03 & 0.02 & 0.08 & 0.00 & 0.03 & 0.01 & 0.09 \\
\hline Population who have lived in the area for the past 10 years (\%) & 0.07 & 0.01 & 0.03 & 0.07 & 0.07 & 0.00 & 0.04 & 0.03 & 0.12 & 0.01 & 0.04 & 0.01 & 0.11 \\
\hline Population who have lived in the area for the past 20 years (\%) & 0.08 & 0.02 & 0.03 & 0.07 & 0.08 & 0.00 & 0.05 & 0.03 & 0.15 & 0.01 & 0.05 & 0.01 & 0.13 \\
\hline Population who have lived in the area for over 20 years $(\%)$ & 0.07 & 0.02 & 0.04 & 0.05 & 0.08 & 0.00 & 0.08 & 0.03 & 0.09 & 0.01 & 0.05 & 0.02 & 0.15 \\
\hline
\end{tabular}


Table A2. The land use area of each indicator for each residential cluster.

\begin{tabular}{|c|c|c|c|c|c|c|c|c|c|c|c|c|c|}
\hline Heading & 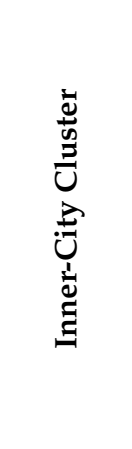 & 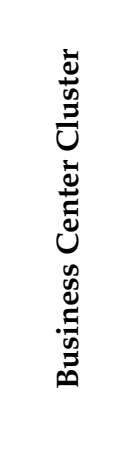 & 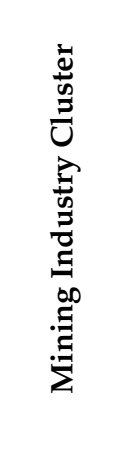 & 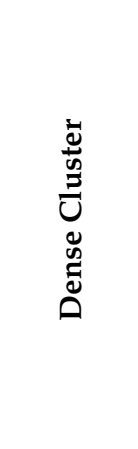 & 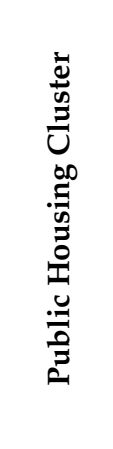 & 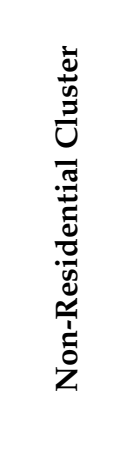 & 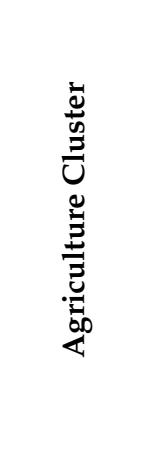 & 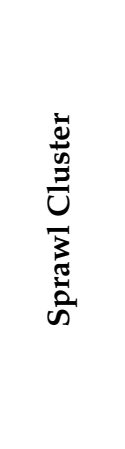 & 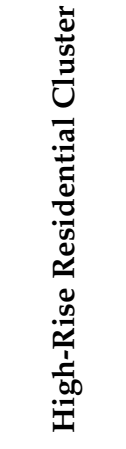 & 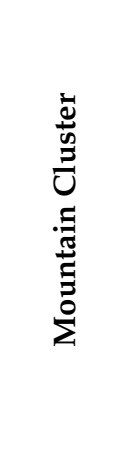 & 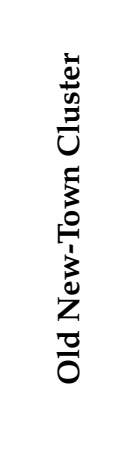 & 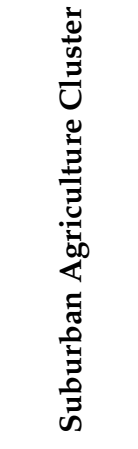 & 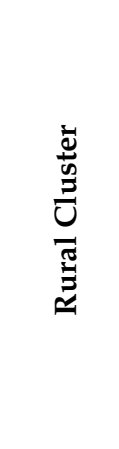 \\
\hline Public facilities land $\left(\mathrm{m}^{2}\right)$ & 39,637 & 18,936 & 24,393 & 65,205 & 32,639 & 40,830 & 32,143 & 33,208 & 41,080 & 17,951 & 23,897 & 19,784 & 34,391 \\
\hline Low-rise residential land $\left(\mathrm{m}^{2}\right)$ & 32,789 & 13,485 & 35,363 & 28,848 & 19,301 & 3504 & 111,001 & 26,419 & 48,553 & 17,373 & 39,973 & 41,492 & 72,239 \\
\hline High-rise residential land $\left(\mathrm{m}^{2}\right)$ & 9053 & 1632 & 4380 & 14,971 & 39,734 & 583 & 525 & 3654 & 21,313 & 807 & 4928 & 701 & 6887 \\
\hline Park green land $\left(\mathrm{m}^{2}\right)$ & 11,649 & 5947 & 9426 & 10,631 & 14,580 & 13,580 & 41,421 & 7421 & 14,513 & 7716 & 7405 & 15,447 & 17,434 \\
\hline Commercial facilities land $\left(\mathrm{m}^{2}\right)$ & 17,635 & 7810 & 10,736 & 20,405 & 10,950 & 11,914 & 31,938 & 11,282 & 13,067 & 6388 & 7436 & 14571 & 24,132 \\
\hline Dense residential land $\left(\mathrm{m}^{2}\right)$ & 5531 & 1619 & 5025 & 3073 & 2458 & 265 & 4379 & 4163 & 2633 & 1325 & 3540 & 933 & 11,780 \\
\hline Mountain forest land $\left(\mathrm{m}^{2}\right)$ & 109,634 & 205,136 & 419,545 & 196,341 & 56,359 & 652,836 & 2,742,099 & 66,609 & 216,845 & 676,535 & 272,460 & 2120,660 & 628,045 \\
\hline Rice field $\left(\mathrm{m}^{2}\right)$ & 4655 & 3102 & 11,091 & 5342 & 3631 & 10,420 & 248,038 & 5034 & 3573 & 14,977 & 3650 & 107,506 & 46,223 \\
\hline Farm land $\left(\mathrm{m}^{2}\right)$ & 3541 & 1619 & 7553 & 2688 & 3490 & 3963 & 175,850 & 4020 & 3076 & 9034 & 2929 & 73,126 & 35,252 \\
\hline Vacant land $\left(\mathrm{m}^{2}\right)$ & 7493 & 3565 & 9145 & 11,319 & 7761 & 7413 & 60,975 & 6932 & 12,634 & 6345 & 9059 & 23,757 & 23,063 \\
\hline developing land $\left(\mathrm{m}^{2}\right)$ & 275 & 745 & 3244 & 283 & 64 & 5920 & 3203 & 1890 & 355 & 1699 & 2028 & 5318 & 2704 \\
\hline
\end{tabular}




\section{References}

1. Kato, H.; Kanki, K. Development of walkability indicator for visualising smart shrinking-A case study of sprawl areas in North Osaka Metropolitan Region. Int. Rev. Spat. Plan. Sustain. Dev. 2020, 8, 39-58. [CrossRef]

2. Cerin, E.; Saelens, B.E.; Sallis, J.F.; Frank, L.D. Neighborhood environment walkability scale: Validity and development of a short form. Med. Sci. Sports Exerc. 2006, 38, 1682-1691. [CrossRef]

3. Inoue, S.; Murase, N.; Shimomitsu, T.; Ohya, Y.; Odagiri, Y.; Takamiya, T.; Ishii, K.; Katsumura, T.; Sallis, J.F. Association of physical activity and neighborhood environment among Japanese adults. Prev. Med. 2009, 48, 321-325. [CrossRef]

4. Kato, H. Effect of Walkability on Urban Sustainability in the Osaka Metropolitan Fringe Area. Sustainability 2020, $12,9248$. [CrossRef]

5. $\quad$ Leung, N.H.L.; Chu, D.K.W.; Shiu, E.Y.C.; Chan, K.H.; McDevitt, J.J.; Hau, B.J.P.; Yen, H.L.; Li, Y.G.; Ip, D.K.M.; Peiris, J.S.M.; et al. Respiratory virus shedding in exhaled breath and efficacy of face masks. Nat. Med. 2020, 26, 676-680. [CrossRef] [PubMed]

6. Iacus, S.M.; Santamaria, C.; Sermi, F.; Spyratos, S.; Tarchi, D.; Vespe, M. Human mobility and COVID-19 initial dynamics. Nonlinear Dyn. 2020, 101, 1901-1919. [CrossRef] [PubMed]

7. Muto, K.; Yamamoto, I.; Nagasu, M.; Tanaka, M.; Wada, K. Japanese citizens' behavioral changes and preparedness against COVID-19: An online survey during the early phase of the pandemic. PLoS ONE 2020, 15, e0234292. [CrossRef]

8. Barbieri, D.M.; Lou, B.W.; Passavanti, M.; Hui, C.; Hoff, I.; Lessa, D.A.; Sikka, G.; Chang, K.; Gupta, A.; Fang, K.; et al. Impact of COVID-19 pandemic on mobility in ten countries and associated perceived risk for all transport modes. PLoS ONE 2021, 16, e0245886. [CrossRef]

9. Hong, J.; McArthur, D.; Raturi, V. Did Safe Cycling Infrastructure Still Matter During a COVID-19 Lockdown? Sustainability 2020, 12, 8672. [CrossRef]

10. World Health Organization (WHO). Moving around during the COVID-19 Outbreak. Available online: https://who.canto.global/ v/coronavirus/s/MFSQ0?viewIndex=1\&column=document\&id=94covo1rdl4snc0dvh3f7uc956 (accessed on 2 April 2021).

11. Prime Minister of Japan and His Cabinet [COVID-19] Declaration of a State of Emergency in Response to the Novel Coronavirus Disease (7 April 2020). Available online: https://japan.kantei.go.jp/ongoingtopics/_00018.html (accessed on 2 April 2021).

12. The Japan Times. The Coronavirus and Japan's Constitution (14 April 2020). Available online: https://www.japantimes.co.jp/ opinion/2020/04/14/commentary/japan-commentary/coronavirus-japans-constitution/ (accessed on 9 June 2021).

13. Google. COVID-19 Community Mobility Reports. Available online: https://www.google.com/covid19/mobility/ (accessed on 2 April 2021).

14. Mizuno Laboratory. COVID-19 Special Site: Visualization of the Percentage of People Who Refrain from Going Out. Available online: http:/ / research.nii.ac.jp/ \{\}mizuno/ (accessed on 2 April 2021). (In Japanese).

15. European Parliament. National COVID-19 Contact Tracing Apps. Available online: https://www.europarl.europa.eu/RegData/ etudes/BRIE/2020/652711/IPOL_BRI(2020)652711_EN.pdf (accessed on 19 December 2020).

16. González, M.C.; Hidalgo, C.A.; Barabási, A.L. Understanding individual human mobility patterns. Nature 2008, 453, 779-782. [CrossRef]

17. Seike, T.; Mimaki, H.; Hara, Y.; Odawara, R.; Nagata, T.; Terada, M. Research on the applicability of "mobile spatial statistics" for enhanced urban planning. J. City Plan. Inst. Jpn. 2011, 46, 451-456. (In Japanese) [CrossRef]

18. Yamaguchi, H.; Okumura, M.; Kaneda, H.; Habu, K. Damage and recovery process of Kumamoto earthquake in daily staying patterns: Observation by mobile phone GPS data. J. Jpn. Soc. Civ. Eng. Ser. D3 2017, 73, I_105-I_117. (In Japanese) [CrossRef]

19. Jia, J.S.S.; Lu, X.; Yuan, Y.; Xu, G.; Jia, J.M.; Christakis, N.A. Population flow drives spatio-temporal distribution of COVID-19 in China. Nature 2020, 582, 389-394. [CrossRef]

20. Badr, H.S.; Du, H.R.; Marshall, M.; Dong, E.S.; Squire, M.M.; Gardner, L.M. Association between mobility patterns and COVID-19 transmission in the USA: A mathematical modelling study. Lancet Infect. Dis. 2020, 20, 1247-1254. [CrossRef]

21. Yabe, T.; Tsubouchi, K.; Fujiwara, N.; Wada, T.; Sekimoto, Y.; Ukkusuri, S.V. Non-compulsory measures sufficiently reduced human mobility in Tokyo during the COVID-19 epidemic. Sci. Rep. 2020, 10, 18053. [CrossRef] [PubMed]

22. Oishi, S.; Cha, Y.J.; Schimmack, U. The Social Ecology of COVID-19 Cases and Deaths in New York City: The Role of Walkability, Wealth, and Race. Soc. Psychol. Pers. Sci. 2021, 1-10. [CrossRef]

23. Doubleday, A.; Choe, Y.; Isaksen, T.B.; Miles, S.; Errett, N.A. How did outdoor biking and walking change during COVID-19?: A case study of three US cities. PLoS ONE 2021, 16, e0245514. [CrossRef]

24. World Economic Forum. Paris Is Planning to Become a '15-Minute City'. Available online: https:/ /www.weforum.org/videos / paris-is-planning-to-become-a-15-minute-city-897c12513b (accessed on 2 April 2021).

25. Balletto, G.; Ladu, M.; Milesi, A.; Borruso, G. A Methodological Approach on Disused Public Properties in the 15-Minute City Perspective. Sustainability 2021, 13, 593. [CrossRef]

26. Speck, J. Walkable City Rules: 101 Steps to Making Better Places; Island Press: Washington, DC, USA, 2018.

27. National Association of City Transportation Officials. Streets for Pandemic Response \& Recovery. Available online: https: //nacto.org/wp-content/uploads/2020/06/NACTO_Streets-for-Pandemic-Response-and-Recovery_2020-05-26.pdf (accessed on 2 April 2021). 
28. Ministry of Health, Labour and Welfare (MHLW). Press: Ministry of Health, Labour and Welfare and Agoop Sign Agreement on Provision of Information Conducive to COVID-19 Cluster Response. Available online: https://www.mhlw.go.jp/stf/newpage_ 11116.html (accessed on 9 June 2021). (In Japanese).

29. Kato, H. Development of a Spatio-temporal Analysis Method to Support the Prevention of COVID-19 Infection: Space-Time Kernel Density Estimation Using GPS Location History Data. In Urban Informatics for Future Cities; Geertman, S., Pettit, C., Goodspeed, R., Staffans, A., Eds.; Springer Nature: Cham, Switzerland, 2021; pp. 51-67. ISBN 978-3-030-76058-8. (In Press). [CrossRef]

30. Agoop Corporation. Homepage. Available online: https:/ /www.agoop.co.jp/en/ (accessed on 2 April 2021).

31. LBMA Japan. Guidelines for the Use of Device Location Data. Available online: https://www.lbmajapan.com/guideline (accessed on 2 April 2021). (In Japanese).

32. Osaka Prefecture Government. Outline of Emergency Measures of Osaka Prefecture. Available online: http://www.pref.osaka.lg jp/attach/38687/00000000/0407_(EN)Emergency\%20Measures\%20of\%20Osaka\%20Prefecture.pdf (accessed on 9 April 2021).

33. Cressie, N. The origins of kriging. Math. Geol. 1990, 22, 239-252. [CrossRef]

34. Requia, W.J.; Coull, B.A.; Koutrakis, P. Evaluation of predictive capabilities of ordinary geostatistical interpolation, hybrid interpolation, and machine learning methods for estimating PM2.5 constituents over space. Environ. Res. 2019, 175, 421-433. [CrossRef]

35. Amobi, O.; Akinyemi, A.; Abiye, K.; Obanubi, C.; James, E.; Gado, P.; Odezugo, G.; Ogundehin, D.; Magaji, D.; Russell, M. Using Supervised Machine Learning and Empirical Bayesian Kriging to Reveal Correlates and Patterns of COVID-19 Disease Outbreak in Sub-Saharan Africa: Exploratory Data Analysis (19 April 2020). Available online: https:/ / ssrn.com/abstract=3580721 (accessed on 5 April 2021). [CrossRef]

36. Gribov, A.; Krivoruchko, K. New Flexible Non-parametric Data Transformation for Trans-Gaussian Kriging. In Geostatistics Oslo 2012 Quantitative Geology and Geostatistics; Springer: Dordrecht, The Netherlands, 2012; Volume 17, pp. 51-65.

37. Gribov, A.; Krivoruchko, K. Empirical Bayesian kriging implementation and usage. Sci. Total Environ. 2020, $772,137290$. [CrossRef]

38. Krivoruchko, K.; Gribov, A. Evaluation of empirical Bayesian kriging. Spat. Stat. 2019, 32, 100368. [CrossRef]

39. Conservation GIS-Consortium Japan. GIS Data. Available online: http://cgisj.jp/download_type_list.php (accessed on 14 April 2020). (In Japanese).

40. E-Stat. Japanese Census Data in 2015. Available online: https:/ /www.e-stat.go.jp/ (accessed on 14 June 2020). (In Japanese).

41. Kato, H. How Does the Location of Urban Facilities Affect the Forecasted Population Change in the Osaka Metropolitan Fringe Area? Sustainability 2021, 13, 110. [CrossRef]

42. Ibaraki City Government. Change of Bus Schedule Due to the Spread of COVID-19 Infection. Available online: https://www.city. ibaraki.osaka.jp/kurashi/machi/doro_kotsu/kokyokotsu/1332902719970.html (accessed on 5 April 2021). (In Japanese).

43. au Insurance Company. A Survey on Bicycle Use During the COVID-19 Pandemic. Available online: https://www.au-sonpo.co. jp/corporate/news/detail-248.html (accessed on 5 April 2021). (In Japanese).

44. Ibaraki City Government. Bicycle Tour in the Northern Ibaraki City. Available online: https:/ /www.city.ibaraki.osaka.jp/kikou/ toshiseibi/hokubuseibi/menu/hokubumiryoku/ibakitameguri/cycling.html (accessed on 5 April 2021). (In Japanese).

45. Mobile Marketing Data Labo. Survey on Food Delivery Services on the Internet in 2020. Available online: https://mmdlabo.jp/ investigation/detail_1871.html (accessed on 5 April 2021). (In Japanese).

46. IBAR EATS. About IBAR EATS. Available online: https://ibar-eats.com/ (accessed on 5 April 2021). (In Japanese).

47. Transport for London. Streetspace for London. Available online: https://tfl.gov.uk/travel-information/improvements-andprojects/streetspace-for-london (accessed on 5 April 2021).

48. Chapman, R.; Keall, M.; Howden-Chapman, P.; Grams, M.; Witten, K.; Randal, E.; Woodward, A. A Cost Benefit Analysis of an Active Travel Intervention with Health and Carbon Emission Reduction Benefits. Int. J. Environ. Res. Public Health 2018, 15, 962. [CrossRef] [PubMed]

49. Osaka Prefectural Police. Location of Traffic Accidents in the Southern Part of Ibaraki City [Map of All Traffic Accidents]. Available online: https:/ / www.police.pref.osaka.lg.jp/kotsu/jiko/3/1/10143.html (accessed on 5 April 2021). (In Japanese).

50. Zhang, J.; Feng, B.; Wu, Y.; Xu, P.; Ke, R.; Dong, N. The effect of human mobility and control measures on traffic safety during COVID-19 pandemic. PLoS ONE 2021, 16, e0243263. [CrossRef]

51. Portland Plan. 20-Minute Neighborhoods. Available online: https:/ /www.portlandonline.com/portlandplan/index.cfm?a=2880 $98 \& c=52256$ (accessed on 5 April 2021).

52. Japanese MILT (Ministry of Land, Infrastructure, Transport and Tourism). National Land Information Download Service. Available online: http:/ / nlftp.mlit.go.jp/ksj/index.html (accessed on 14 March 2020).

53. Geospatial Information Authority of Japan. The Numerical Map 5000 in Japan (in Osaka Metropolitan Area). Available online: https:/ / www.gsi.go.jp/kankyochiri/lum-5k.html (accessed on 1 April 2020). (In Japanese). 